\title{
ATUAL ESTÁGIO DE DESENVOLVIMENTO DA TECNOLOGIA GTL E PERSPECTIVAS PARA O BRASIL
}

\author{
André Luis Dantas Ramos*, José Jailton Marques e Vagner dos Santos \\ Departamento de Engenharia Química, Universidade Federal de Sergipe, Av. Mal. Rondon, s/n, 49100-000 São Cristóvão - SE, Brasil \\ Lisiane dos Santos Freitas e Rosanne Graziele Vieira de Melo Santos \\ Engenharia de Processos, Universidade Tiradentes, Av. Murilo Dantas, 300, 49032-490 Aracaju - SE, Brasil \\ Mariana de Mattos Vieira Mello Souza \\ Escola de Química, Universidade Federal do Rio de Janeiro, Centro de Tecnologia, Bl. E, Ilha do Fundão, 21941-909 Rio de \\ Janeiro - RJ, Brasil
}

Recebido em 22/10/10; aceito em 10/3/11; publicado na web em 5/5/11

\begin{abstract}
CURRENT STAGE OF DEVELOPMENT OF GTL TECHNOLOGY AND PERSPECTIVES FOR BRAZIL. Although the production of liquid fuels from coal, natural gas (CTL and GTL processes) and other carbon sources has been discovered 90 years ago, the interest was renewed in the last years motivated by stranded gas reserves and by petroleum market instability. This review intends to show the scenario of these technologies nowadays, discussing the applied technologies, the steps in an industrial plant, the ways to produce syngas and liquid fuels, the catalysts used, the type of reactors and the operating plants with their respective capacities, besides the technical, economical and environmental viability, challenges and perspectives for Brazil.
\end{abstract}

Keywords: natural gas; gas-to-liquid; Fischer-Tropsch.

\section{INTRODUÇÃO}

Desde a Revolução Industrial, o crescimento da sociedade está diretamente relacionado à transformação de energia e produção de combustíveis, principalmente a partir do petróleo. No entanto, segundo especialistas, a produção global de petróleo deve atingir seu pico entre 2010-20201 e, dentro desse prazo, metade das reservas recuperáveis de petróleo terá sido processada. Os especialistas acreditam que quando a produção global atingir o seu pico, praticamente todas as reservas inexploradas estarão no Oriente Médio. Além disso, uma crise na produção de petróleo poderia impulsionar a sociedade a recorrer a combustíveis ainda mais poluentes como o carvão, o óleo pesado e a areia de alcatrão (tar sands), o que representaria sérias consequências ao meio ambiente. ${ }^{2}$

O gás natural surge como uma alternativa, sendo que uma grande parte dele é produzida mundialmente de forma associada ao petróleo. A queima deste gás em queimadores em áreas de exploração marítimas é uma prática que agride o meio ambiente, visto que a combustão do gás natural emite diversos poluentes para atmosfera, tais como material particulado, óxidos de enxofre $\left(\mathrm{SO}_{\mathrm{x}}\right)$ e nitrogênio $\left(\mathrm{NO}_{\mathrm{x}}\right)$, dentre outros. É controlada tanto pelos órgãos ambientais quanto pela Agência Nacional de Petróleo (ANP), através do Programa Anual de Produção, que determina o volume de gás que pode ser queimado, perdido ou ventilado para cada campo. ${ }^{3}$ Estas restrições podem gerar um impeditivo às atividades de exploração e produção (E\&P), inclusive para descobertas recentes de petróleo na região do pré-sal. Para que um poço seja considerado viável do ponto de vista econômico, é necessário realizar os chamados testes de longa duração (TLD), para verificar a produção contínua de petróleo pelo poço. O gás natural associado é produzido por estes testes e, além das restrições de queima, a distância entre as plataformas e o continente pode tornar inviável a construção de dutos no oceano para o escoamento desse gás.

*e-mail: aldramos@ufs.br
Outra prática que é controlada pelos órgãos governamentais é a produção de combustíveis, pois se exige que os mesmos atendam a especificações mais severas e, consequentemente, menos poluentes. Os altos índices de material particulado que são emitidos durante a combustão dos derivados estão relacionados diretamente com problemas respiratórios, assim como componentes nitrogenados, aromáticos e sulfurados se relacionam a doenças cancerígenas. ${ }^{4,5}$ Além disso, a presença de compostos nitrogenados e de enxofre está relacionada com emissões de $\mathrm{SO}_{x}$ e $\mathrm{NO}_{x}$, responsáveis por alguns efeitos globais, tais como as chuvas ácidas e a destruição da camada de ozônio.

Dessa forma, surge a necessidade de se buscar alternativas que conciliem o avanço tecnológico ao desenvolvimento sustentável, em particular para que a indústria petrolífera seja beneficiada com o aproveitamento das reservas remotas. É nessa conjuntura que a tecnologia de produção de combustíveis líquidos a partir do gás natural (tecnologia GTL - gas to liquid) através da síntese Fischer-Tropsch (F-T) pode ser considerada como o refino do futuro, pois permite obter combustíveis para motores a diesel de alta qualidade, nafta petroquímica, bases para lubrificantes e alfa-olefinas de alta qualidade, desprovidos de metais pesados e compostos nitrogenados presentes no petróleo. ${ }^{6}$

A presente revisão pretende mostrar o quadro atual das tecnologias de produção de combustíveis líquidos a partir de fontes de carbono como o gás natural, abordando as modalidades aplicadas, as etapas envolvidas nas plantas, as formas de produzir gás de síntese e combustíveis líquidos, os catalisadores utilizados, os tipos de reatores e o número de plantas existentes com suas respectivas capacidades instaladas, passando pela abordagem da viabilidade técnica, econômica e ambiental da tecnologia e mostrando os desafios e perspectivas da mesma no Brasil.

\section{HISTÓRICO DO PROCESSO FISCHER-TROPSCH (F-T)}

O histórico do processo F-T remonta ao período da $1^{\mathrm{a}}$ Guerra Mundial em que a Alemanha, país carente de recursos petrolíferos, 
sofreu embargo dos países rivais, tendo a necessidade de desenvolver uma fonte alternativa de combustíveis que fosse baseada no carvão, riqueza mineral disponível na região. Nesse período, foram realizadas as primeiras descobertas relacionadas ao processo F-T, através dos cientistas alemães Franz Fischer e Hans Tropsch, que introduziram o processo de conversão do gás de síntese, produzido a partir do carvão, em combustíveis líquidos (coal to liquids-CTL), por volta de $1923 .{ }^{7}$ No entanto, a tecnologia primitiva era cara e ineficiente e não podia competir com a tecnologia barata e abundante de petróleo bruto. ${ }^{8}$

Nos anos 50, período das grandes descobertas de petróleo, o emprego de tecnologias que usavam o carvão como insumo entrou em desuso. Neste período, conhecido como "idade do petróleo", o cenário energético mundial era regulado por uma abundância e oferta de petróleo barato. Como consequência, o processo F-T perdeu um pouco de interesse, sendo exceção a indústria sul-africana Sasol, criada em 1950, que continuou interessada na tecnologia, baseando-se numa matéria-prima extremamente barata e doméstica (o carvão) e em políticas do estado, em um país sem grandes reservas de petróleo bruto. ${ }^{9}$ A África do Sul merece atenção especial por participar ativamente, até os dias atuais, do ressurgimento e retomada da síntese de F-T.

No final dos anos 60 e início dos anos 70, motivada pela crise do petróleo, devido ao embargo árabe em 1972, a tecnologia F-T voltou ao cenário mundial como uma forma alternativa de produzir combustíveis líquidos. Isto representou uma oportunidade para a Sasol utilizar os conhecimentos acumulados nesta reação. A empresa sul-africana considera o seu background na tecnologia F-T uma das cinco forças motrizes fundamentais do seu crescimento. ${ }^{10}$

Com as questões da preservação ambiental em alta, a partir dos anos 90, observa-se a presença do processo F-T como uma forma de se produzir combustíveis menos poluentes e também de aproveitar as reservas de gás natural. Além disso, no caso dos países que utilizam o carvão, as grandes minas abandonadas poderiam produzir matéria-prima com preços bastante competitivos para revigorar o processo GTL. ${ }^{11}$

Dessa forma, o cenário atual mostra o desenvolvimento de projetos para a construção de plantas GTL e uma busca por aperfeiçoamento de uma tecnologia já existente e bem estabelecida, assim como a descoberta de novas tecnologias que visem otimizar as etapas. $\mathrm{O}$ desenvolvimento de equipamentos mais modernos e menores, recuperação de energia e desenvolvimento dos catalisadores têm sido o foco principal da busca das empresas. ${ }^{12}$

\section{USO E TRANSFORMAÇÕES DO GÁS NATURAL}

Acredita-se que o modelo de energia atual, com base no petróleo, passará por consideráveis modificações, com a contribuição do gás natural como matéria-prima para insumos ficando cada vez maior. ${ }^{13}$ Assim, é importante mostrar a matriz de produtos que o gás natural pode gerar.
O gás natural produzido, seja em poços terrestres ou marítimos, é submetido ao processamento primário, no qual é feita a separação óleo/gás/água. Nas Unidades de Processamento de Gás Natural (UPGN) é realizada a separação das frações pesadas $\left(\mathrm{C}_{3}{ }^{+}\right)$do metano e etano $\left(\mathrm{C}_{1}+\mathrm{C}_{2}\right)$, gerando GLP $\left(\mathrm{C}_{3}+\mathrm{C}_{4}\right)$ e gasolina natural $\left(\mathrm{C}_{5}{ }^{+}\right)$.

$A$ fração $C_{1}+C_{2}$ é denominada gás residual, industrial ou seco. Pode ser consumida na elevação artificial de petróleo ( gas lift); na injeção em poços - recuperação secundária; como combustível (GNV) ou industrialmente. Na indústria, uma das principais aplicações é a produção de metanol, dimetil éter e amônia, todos via gás de síntese. Também é utilizado como matéria-prima na indústria petroquímica para a produção de eteno e propeno e na produção de hidrogênio na indústria de refino. Outra utilização é como combustível para geração de energia elétrica.

Com relação ao transporte, o gás natural pode ser transportado através do uso de várias tecnologias, tais como gás natural comprimido (GNC), gás natural adsorvido (GNA) e gás natural liquefeito (GNL). Outras tecnologias não transportam o gás propriamente dito, mas surgem como uma solução para o problema de seu transporte, com o gás passando por alguma etapa de transformação, tais como a gas to solid (GTS) - hidratos, gas to wire (GTW) - geração de eletricidade e gas to liquid (GTL) - transformação química do gás natural em combustíveis líquidos, foco desta revisão.

A indústria de GNL tem crescido rapidamente e a indústria de GTL tem perspectiva de se expandir a um ritmo igual e até mesmo superior àquela. Isso decorre de vários fatores, dentre os quais a desvantagem do GNL com relação ao GTL, visto que precisa ser consumido em grandes quantidades para justificar o investimento em toda sua infraestrutura. O transporte do GNL é feito através de navios, barcaças e/ou caminhões criogênicos a uma temperatura de - $161,5^{\circ} \mathrm{C}$, sendo o volume do gás reduzido para 1/600 vezes do seu volume original à temperatura ambiente. ${ }^{8}$

\section{A TECNOLOGIA GTL - UMA VISÃO GERAL}

As configurações dos processos envolvendo a tecnologia GTL variam em função dos propósitos da planta. A Figura 1 mostra um diagrama de fluxo simplificado de uma planta GTL. ${ }^{14,15}$

A tecnologia GTL envolve três etapas básicas: produção de gás de síntese - syngas $\left(\mathrm{CO}+\mathrm{H}_{2}\right)$ a partir de uma fonte de carbono, em reações denominadas por reformas; transformação do gás de síntese em hidrocarbonetos a partir do processo Fischer-Tropsch, com o objetivo de formar hidrocarbonetos de maior massa molar por meio de reações exotérmicas; etapa de upgrading, no qual são obtidos os produtos finais, podendo se valer dos processos tradicionais de refino como hidrotratamento, isomerização, dentre outros. Nessa etapa, o objetivo se concentra em decompor hidrocarbonetos de altas massas molares em moléculas menores, na faixa desejada: nafta, óleo diesel, parafinas, dentre outros. Estas etapas serão discutidas detalhadamente a seguir.

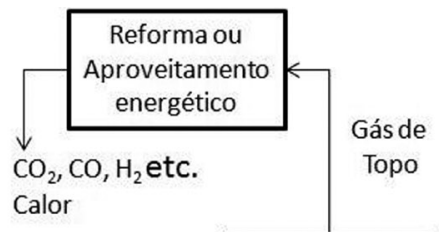

Fonte de C

(Ex: gás natural, carvão, biomassa)

\section{Gás de Síntese Síntese de $\mathrm{CO}+\mathrm{H}_{2} \rightarrow$ Fischer- \\ Fischer-
Tropsch}

Tós de

Reforma

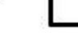

政
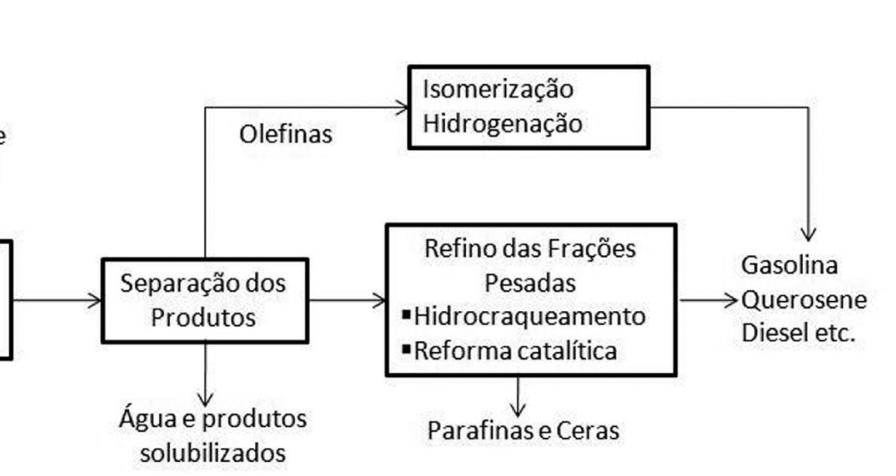


\section{Tecnologias de produção de gás de síntese}

O gás de síntese, um intermediário chave na indústria química, é uma mistura de hidrogênio, monóxido de carbono e dióxido de carbono, que pode ser usada em diversas sínteses de produtos químicos e combustíveis e como fonte de hidrogênio puro ou monóxido de carbono.

O gás de síntese pode ser produzido a partir de praticamente qualquer fonte de carbono, tais como gás natural, óleos pesados, carvão e até biomassa. ${ }^{2}$ Atualmente o gás natural constitui a principal matéria-prima para a produção de gás de síntese, devido à disponibilidade das reservas mundiais e os investimentos são cerca de $1 / 3$ de uma planta baseada no carvão. Além disto, a reforma do metano é muito mais eficiente do que a gaseificação do carvão, por conta do menor teor de hidrogênio presente neste. ${ }^{6}$

Em plantas GTL baseadas em gás natural a produção do gás de síntese representa cerca de $60 \%$ do investimento. ${ }^{16}$ Portanto, há um grande interesse na otimização dessa etapa do processo, a fim de reduzir os custos.

\section{Produção a partir do gás natural}

A produção de gás de síntese requer razões $\mathrm{H}_{2} / \mathrm{CO}$ adequadas para as etapas industriais seguintes, como síntese de Fischer-Tropsch, produção de metanol, etc. Estas diferentes razões de $\mathrm{H}_{2} / \mathrm{CO}$ podem ser obtidas através de três processos principais:

\section{Reforma com vapor}

É o processo mais utilizado industrialmente para a produção de gás de síntese:

$$
\mathrm{CH}_{4}+\mathrm{H}_{2} \mathrm{O} \rightleftarrows \mathrm{CO}+3 \mathrm{H}_{2} \quad \Delta \mathrm{H}_{298 \mathrm{~K}}=206 \mathrm{~kJ} / \mathrm{mol}
$$

Possui alta eficiência térmica ( $>80 \%$ ), consumindo cerca de 10 a $12 \mathrm{t}$ de vapor por tonelada de $\mathrm{H}_{2}$ produzido, mas seus custos de operação são muito altos, pois exige o superaquecimento do vapor a altas temperaturas (cerca de $650-950{ }^{\circ} \mathrm{C}$ ). ${ }^{17}$

Como a reação é fortemente endotérmica, deve-se utilizar altas temperaturas $\left(>800^{\circ} \mathrm{C}\right)$ para se alcançar elevadas conversões, como pode ser visto na Figura 2. Assim, cerca de 30-40\% do gás natural é utilizado como combustível para geração de energia, provocando grandes emissões de $\mathrm{CO}_{2}$ (cerca de 0,35 a $0,42 \mathrm{~m}^{3}$ de $\mathrm{CO}_{2}$ por $\mathrm{m}^{3}$ de $\mathrm{H}_{2}$ produzido).

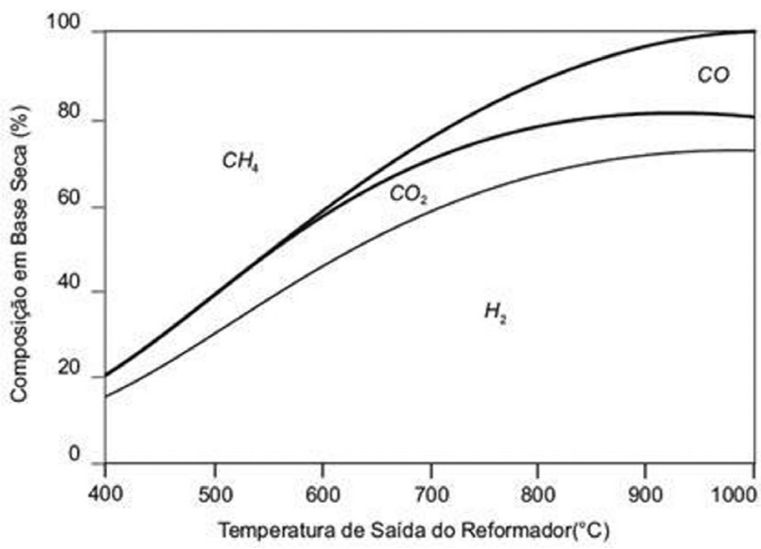

Figura 2. Composição de equilíbrio de um reformador operando a 26 bar e com razão $\mathrm{H}_{2} \mathrm{O} / \mathrm{CH}_{4}=2,5$

Embora a estequiometria da reação seja de 1 mol de vapor por mol de metano, excesso de vapor é normalmente utilizado (razão $\mathrm{H}_{2} \mathrm{O}$ /
$\mathrm{CH}_{4}$ entre 2,5 e 5), para se reduzir a formação de carbono residual (coque) sobre o catalisador e aumentar a conversão do metano. ${ }^{18}$ Porém, quanto menor a razão $\mathrm{H}_{2} \mathrm{O} / \mathrm{CH}_{4}$, menor é o tamanho dos equipamentos e maior a eficiência energética, reduzindo os custos operacionais. A diminuição da conversão do metano em menor relação $\mathrm{H}_{2} \mathrm{O} / \mathrm{CH}_{4}$ pode ser compensada pelo aumento da temperatura de saída do reformador.

A reação de reforma ocorre normalmente em temperaturas de $750-900{ }^{\circ} \mathrm{C}$ e pressão de $15-30$ bar. Muitas vezes se utiliza um reformador secundário, onde se injeta oxigênio para converter o metano não reagido no reformador primário.

No reformador principal usualmente utilizam-se catalisadores de níquel (15-20\% Ni) suportados em material refratário (ex: $\alpha-\mathrm{Al}_{2} \mathrm{O}_{3}$ ), contendo promotores alcalinos $(\mathrm{K})$ ou alcalino terrosos $(\mathrm{Mg}, \mathrm{Ca})$, que aceleram a remoção do coque da superfície catalítica. A utilização de metais nobres (ex: platina) em catalisadores de reforma tem-se mostrado extremamente atrativa, pois, apesar do maior custo, a atividade e estabilidade são bem superiores aos catalisadores de níquel. ${ }^{19}$

O tipo de reformador mais utilizado é o tubular. Esse reator consiste de uma seção de radiação, onde o catalisador se encontra em diversos tubos paralelos, dispostos dentro de um forno aquecido por queimadores, e uma seção de convecção, onde é feita a recuperação de calor dos gases quentes efluentes da seção de radiação. Cerca de $50 \%$ do calor transferido ao forno é recuperado dos gases efluentes, sendo usado para a produção de vapor e pré-aquecimento dos gases de alimentação do reformador e do ar de combustão. ${ }^{20}$

Em relação aos queimadores, eles podem estar dispostos em quatro configurações distintas, de acordo com a Figura 3, que são descritas a seguir: ${ }^{18}$
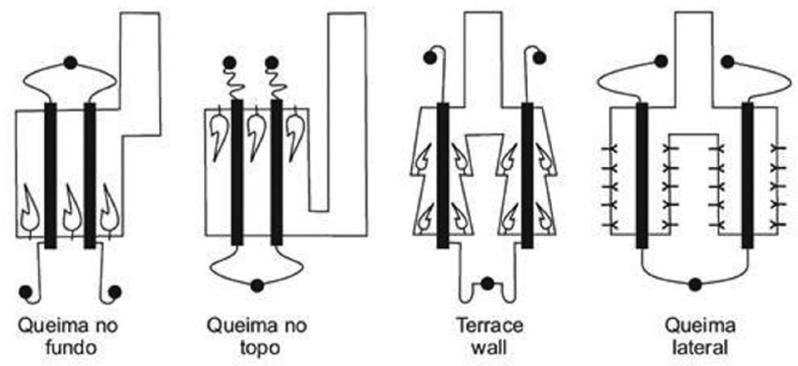

Figura 3. Tipos de queima num reformador tubular

- Queima no topo (tecnologia da KTI, Lummus e Uhde): caracterizada pela existência de um pico no perfil de temperatura da parede do tubo na parte superior do reformador. Este arranjo possui maior fluxo de calor nos pontos de maior temperatura. $\mathrm{O}$ pequeno número de queimadores permite uma grande capacidade (600 a 1000 tubos) em uma montagem compacta.

- Queima lateral (tecnologia da KTI e Topsoe): o calor pode ser perfeitamente distribuído para qualquer capacidade (maior flexibilidade de projeto e operação, maior fluxo médio de calor). A temperatura máxima é obtida na saída do tubo, enquanto que o fluxo de calor máximo é obtido a uma temperatura relativamente baixa. O grande número de queimadores e a complexidade de distribuição do combustível e do ar limitam a sua capacidade (100-150 tubos).

- Terrace wall (tecnologia da Foster Wheeler): os dois ou três leitos de queimadores permitem que o aquecimento seja ajustado a diferentes taxas.

- Queima no fundo (raramente usada): apresenta um perfil de fluxo de calor praticamente constante ao longo do comprimento dos tubos. Tem baixa eficiência térmica e alta temperatura de 
parede, especialmente quando se desja baixo conteúdo residual de metano.

Existe também o reformador convectivo, que permite aumentar a quantidade de calor transferida ao gás de processo de 50 para $80 \%$ do calor suprido ao reformador. Nesse caso, o gás de processo é aquecido em contracorrente pelos gases de combustão no lado externo dos tubos e também pelo gás reformado no lado interno. As vantagens do reformador convectivo são a maior compacidade, maior eficiência de troca de calor e resposta mais rápida.

\section{$\underline{\text { Reforma } \operatorname{com} \mathrm{CO}_{2}}$}

A reforma com $\mathrm{CO}_{2}$ (Equação 2) possui algumas vantagens que a tornam atrativa:

$$
\mathrm{CH}_{4}+\mathrm{CO}_{2} \rightleftarrows \mathrm{CO}+\mathrm{H}_{2} \quad \Delta \mathrm{H}_{298 \mathrm{~K}}=247 \mathrm{~kJ} / \mathrm{mol}
$$

custos totais de operação e de investimento inferiores ao do processo com vapor, ${ }^{21}$ produz gás de síntese com menor razão $\mathrm{H}_{2} / \mathrm{CO}$ (próxima a 1), o que é mais adequado à hidroformilação, síntese de ácido acético e éter dimetílico (usado como combustível alternativo para motores a diesel) e para a obtenção de $\mathrm{CO}$ puro, usado na produção de policarbonatos; tem grande apelo ambiental, pois reduz as emissões de $\mathrm{CO}_{2} \mathrm{e} \mathrm{CH}_{4}$, gases que contribuem para o efeito estufa.

Alguns processos industriais de produção de gás de síntese utilizam a reforma $\mathrm{CH}_{4}-\mathrm{CO}_{2}$, como o processo CALCOR da Caloric $\mathrm{GmbH}^{22}$ e o processo SPARG da Haldor-Topsoe..$^{23}$

A principal desvantagem da reforma com $\mathrm{CO}_{2}$ é o maior risco de desativação do catalisador pela formação de coque, devido ao maior conteúdo carbonáceo da carga. ${ }^{24}$ Para a mesma razão $\mathrm{CO}_{2} / \mathrm{CH}_{4}$ de alimentação, a temperatura limite para evitar a deposição de carbono aumenta se a pressão aumenta. O aumento da pressão aumenta a tendência de formação de coque, pela própria termodinâmica da reação de desproporcionamento de $\mathrm{CO}$ (Equação 3): como o carbono formado é sólido, a reação direta ocorre com redução de volume e um aumento de pressão desloca o equilíbrio para a direita. Para uma dada pressão, a temperatura limite aumenta se a razão $\mathrm{CO}_{2} / \mathrm{CH}_{4}$ diminui. Com isso, um excesso de $\mathrm{CO}_{2}$ na alimentação minimiza a formação de coque.

$$
2 \mathrm{CO} \rightleftarrows \mathrm{CO}_{2}+\mathrm{C} \quad \Delta \mathrm{H}_{298 \mathrm{~K}}=-172 \mathrm{~kJ} / \mathrm{mol}
$$

\section{$\underline{\text { Reforma autotérmica }}$}

As principais dificuldades apresentadas pelos processos anteriores são a demanda energética das reações e a tendência à formação de coque no sistema. Visando a redução da demanda energética, é recomendável combinar a reação de reforma (com vapor ou $\mathrm{CO}_{2}$ ) à oxidação parcial do metano (Equação 4).

$$
\mathrm{CH}_{4}+1 / 2 \mathrm{O}_{2} \rightleftarrows \mathrm{CO}+2 \mathrm{H}_{2} \quad \Delta \mathrm{H}_{298 \mathrm{~K}}=-36 \mathrm{~kJ} / \mathrm{mol}
$$

A combinação das reações de oxidação parcial e reformas com vapor d'água ou $\mathrm{CO}_{2}$ é de grande interesse industrial pela possibilidade de poder se desenvolver um processo favorável energeticamente, uma vez que as reações de reforma são endotérmicas e a oxidação é exotérmica. A energia liberada pela oxidação é aproveitada na reação de reforma, sendo por isso o processo chamado de autotérmico.

Através de um estudo comparativo dos custos dos diferentes processos de obtenção de gás de síntese, considerando o consumo de matéria-prima, o consumo de energia, investimentos e custos operacionais, os resultados indicaram que o processo convencional de reforma com vapor é o mais dispendioso, enquanto a reforma autotérmica pode chegar a apresentar custo $18 \%$ inferior aos demais processos..$^{25}$
A razão $\mathrm{H}_{2} / \mathrm{CO}$ produzida no processo de reforma a vapor é cerca de 3 , muito alta para o processo GTL, que requer razões da ordem de 2. Uma grande vantagem da reforma autotérmica é a possibilidade de se obter a razão $\mathrm{H}_{2} / \mathrm{CO}$ desejada pelo ajuste das quantidades de $\mathrm{CH}_{4}, \mathrm{H}_{2} \mathrm{O}$ (ou $\mathrm{CO}_{2}$ ) e $\mathrm{O}_{2}$ na carga. Essa flexibilidade e o menor custo fazem com que esse processo seja, atualmente, o mais indicado para aplicações GTL tradicionais. ${ }^{26}$

A reforma autotérmica foi inicialmente desenvolvida pela Haldor Topsoe (Figura 4), como uma combinação da oxidação parcial não catalítica do metano com a reforma com vapor. ${ }^{20}$ A relação $\mathrm{H}_{2} \mathrm{O} / \mathrm{C}$ usada é de cerca de 0,6 ; com isso, a razão $\mathrm{H}_{2} / \mathrm{CO}$ produzida se aproxima de 2 e se reduz o reciclo de $\mathrm{CO}_{2}$. Uma alta temperatura de entrada e baixa temperatura de saída no reator reduzem o consumo de $\mathrm{O}_{2}$. Uma baixa temperatura de saída aumenta a razão $\mathrm{H}_{2} / \mathrm{CO}$ produzida.

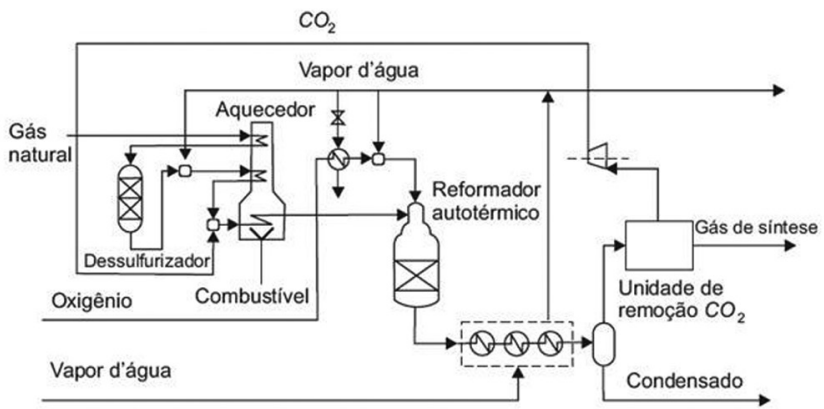

Figura 4. Fluxograma do processo de reforma autotérmica da Haldor-Topsoe

O reformador autotérmico utilizado pela Haldor-Topsoe consiste de três seções: uma de queima, onde o queimador proporciona a mistura das correntes numa chama turbulenta; uma de combustão, onde ocorre a combustão do metano em fase homogênea, a altas temperaturas (cerca de $1900{ }^{\circ} \mathrm{C}$ ) e uma seção de catálise, onde a reação de reforma é catalisada por níquel, com temperatura entre 900 e $1100{ }^{\circ} \mathrm{C} .{ }^{27}$ As severas condições operacionais requerem um catalisador com altas estabilidades térmica e mecânica.

Posteriormente, outras configurações para o processo autotérmico foram propostas. O processo da ICI consiste de dois reatores de leito fixo em série, onde o primeiro é dedicado à reforma com vapor, ocorrendo no segundo a oxidação parcial catalítica do metano não reagido na reforma com vapor, em um catalisador monolítico. $\mathrm{O}$ calor requerido pela reforma primária é fornecido pelo gás proveniente do reformador secundário. Segundo os fabricantes, o tamanho da unidade de geração de gás de síntese é cerca de $25 \%$ menor, reduzindo assim os custos de capital. No processo da UHDE, a reforma e oxidação parcial não catalítica são combinadas numa única etapa. Uma parte da alimentação, juntamente com vapor, é levada aos tubos de reforma (contendo catalisador tradicional de reforma) e outra parte é direcionada a uma câmara de oxidação parcial, juntamente com $\mathrm{O}_{2}$. Os gases que deixam a câmara fornecem calor para a reforma nos tubos. ${ }^{28}$

\section{Produção a partir da biomassa}

Nos últimos anos o uso de fontes renováveis de energia tem recebido grande atenção como alternativa aos combustíveis fósseis. A biomassa é a única fonte renovável de material carbonáceo e a produção de combustíveis a partir desta fonte, seja biomassa residual ou não, pode reduzir ou mesmo anular as emissões de $\mathrm{CO}_{2}$, que é o principal causador do efeito estufa. $\mathrm{O}$ termo biomassa se refere em sentido amplo a qualquer tipo de matéria orgânica renovável de origem vegetal, animal ou procedente da transformação natural ou artificial da mesma. Estes materiais têm em comum a origem direta ou indireta do processo de fotossíntese. 
A produção de gás de síntese a partir de biomassa é feita principalmente através da gaseificação, um processo termoquímico que envolve a conversão de material carbonáceo, produzindo gás combustível, voláteis, carvão e cinza. Ocorre a reação do carbono com ar, oxigênio, vapor d'água, dióxido de carbono, ou uma mistura destes gases na temperatura mínima de $700{ }^{\circ} \mathrm{C}$. A gaseificação ocorre em condições subestequiométricas, com suprimento de oxigênio controlado (cerca de $35 \%$ do requerido para a combustão completa). ${ }^{29}$

A gaseificação é um processo que envolve ao menos duas etapas. Na primeira, denominada pirólise, os componentes dissociáveis e voláteis do combustível são vaporizados em temperaturas inferiores a $600{ }^{\circ} \mathrm{C}$, em uma reação endotérmica. A pirólise é um processo de decomposição térmica em atmosfera inerte e com baixo tempo de contato, que envolve uma sequência de reações de desidratação e despolimerização dos carboidratos e da lignina, representada pela Equação 5:

Biomassa + energia $\rightarrow$ bio-óleo + gases + resíduo carbonáceo

O bio-óleo é a fração líquida produzida. Os gases incluem hidrocarbonetos, $\mathrm{H}_{2}, \mathrm{CO}, \mathrm{CO}_{2}$, vapor d'água e alcatrão. $\mathrm{O}$ resíduo carbonáceo é denominado char e constitui um subproduto altamente refratário.

Na segunda etapa o char pode ser gaseificado $\left(\mathrm{T}>700^{\circ} \mathrm{C}\right)$ através de reações com ar e/ou vapor, gerando energia para a pirólise. ${ }^{30}$

A distribuição dos produtos na gaseificação da biomassa depende de: tipo de biomassa (umidade, poder calorífico), tipo de gaseificador, temperatura, pressão, tempo de residência, agente gaseificante (ar, vapor) e catalisador. Quando o objetivo é produzir gás de síntese $\left(\mathrm{H}_{2}+\mathrm{CO}\right)$, as condições que favorecem o equilíbrio termodinâmico são altas temperaturas e baixas pressões, reciclo de carbono e $\mathrm{CO}_{2} \cdot{ }^{31}$

Diferentes gaseificadores podem ser empregados no processo de gaseificação de biomassa, incluindo os de leito fixo e fluidizado. Os gaseificadores apresentam grandes diferenças de capacidade de produção, temperatura, pressão, diferenças em relação ao sentido dos fluxos de ar e de alimentação, etc. A seleção do tipo de gaseificador é determinada por diferentes fatores, como capacidade do reator e tipo de biomassa a ser processada.

Os gaseificadores de leito fixo são os mais simples e os mais adequados para pequenas unidades. Esses gaseificadores se classificam em contracorrente e cocorrente, segundo as diferentes maneiras com que as etapas de gaseificação podem ocorrer.

No gaseificador de leito fixo em contracorrente o combustível é alimentado pelo topo (através de uma válvula rotativa ou porta de alimentação) e desce em contracorrente ao ar ou oxigênio (misturado com vapor d'água ou $\mathrm{CO}_{2}$ ), introduzido pela grelha localizada na base do gaseificador. As primeiras camadas de biomassa apoiadas sobre a grelha entram em combustão intensa, produzindo $\mathrm{CO}_{2} \mathrm{e}$ $\mathrm{H}_{2} \mathrm{O}$ a temperaturas elevadas, que, posteriormente, são reduzidos a $\mathrm{CO}$ e $\mathrm{H}_{2}$ conforme passam pela camada descendente de biomassa, baixando a temperatura para cerca de $750{ }^{\circ} \mathrm{C}$. Os gases, ao subirem, continuam trocando calor com a corrente de sólidos, promovendo a sua pirólise, com liberação e incorporação à corrente gasosa da matéria volátil do combustível e, em sequência, sofrem aquecimento e secagem. As cinzas do combustível saem pela base do gaseificador. Esses processos podem ser visualizados na Figura 5a. A principal vantagem desse tipo de gaseificador é a simplicidade operacional e habilidade de gaseificar materiais com elevado teor de umidade e material inorgânico, como lodo residual de tratamento de esgoto.

No gaseificador cocorrente a biomassa entra por cima e o ar entra num ponto intermediário e desce no mesmo sentido da biomassa, conforme pode ser visto na Figura 5b. O ar entra na região de combustão e produz uma chama, com a queima de grande parte dos voláteis. Essa
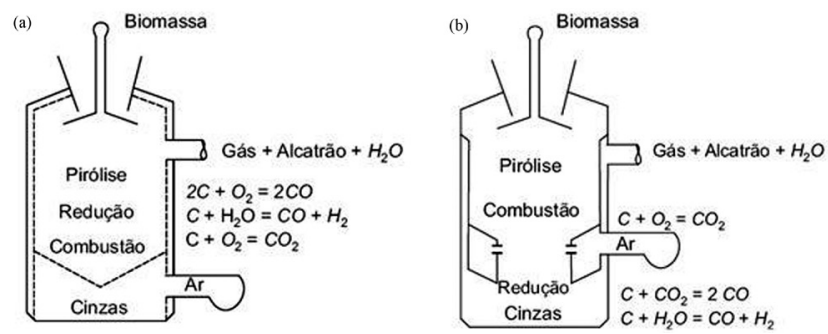

Figura 5. Diagrama esquemático do processo de gaseificação de biomassa em um gaseificador contracorrente (a) e cocorrente (b)

chama é conhecida como combustão pirolítica, onde a quantidade limitada de ar produz gases combustíveis além de gás carbônico e água. Quando os voláteis restantes são obrigados a passar pela zona de combustão, atingem temperaturas altas que os transformam em gases não condensáveis. $\mathrm{O}$ ar injetado no gaseificador pode queimar até 99,9\% do alcatrão liberado pelo combustível e, dessa forma, os gases gerados necessitam apenas de um mínimo de purificação.

\section{TECNOLOGIA FISCHER-TROPSCH}

A síntese Fischer-Tropsch é uma reação catalítica que converte dois dos compostos mais simples da natureza, $\mathrm{H}_{2}$ e $\mathrm{CO}$ (gás de síntese), em uma matriz complexa de produtos, contemplando alquenos (olefinas), alcanos (parafinas) e compostos oxigenados (ex: alcoóis, aldeídos, ácidos carboxílicos e cetonas), além de água. ${ }^{32}$ As parafinas geradas são geralmente de cadeias lineares, desde o metano até ceras, ${ }^{15}$ passando por gasolina, óleo diesel e querosene de aviação, até hidrocarbonetos com até 100 átomos de carbono. ${ }^{33}$ As temperaturas usualmente empregadas na síntese de F-T variam de 200 a $350{ }^{\circ} \mathrm{C} .{ }^{34}$

O mecanismo da síntese F-T sobre catalisadores heterogêneos tem sido amplamente discutido na literatura. ${ }^{35,36}$ Supõe-se que se inicia com a dissociação de $\mathrm{CO}$ e $\mathrm{H}_{2}$ na superfície do metal de transição, o primeiro de forma não dissociativa e o segundo de forma dissociativa, gerando espécies de hidrogênio atômico adsorvidas $\left(\mathrm{H}^{*}\right)$. A Figura 6 mostra as demais etapas.

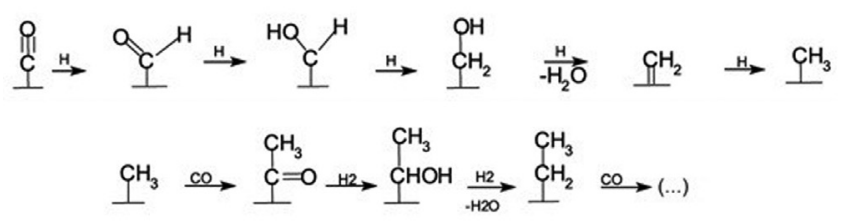

Figura 6. Mecanismo da síntese Fischer-Tropsch na superfície do catalisador

O monóxido de carbono adsorvido forma grupos carbonila adsorvidos. Em seguida, esta espécie sofre hidrogenações sucessivas. Primeiramente se forma um aldeído, depois um álcool. Na quarta adição de $\mathrm{H}^{*}$, uma molécula de água é liberada, formando uma espécie metal-cabeno adsorvida e, na última adição, é gerado um grupo metil. A partir daí, ocorre um processo de crescimento da cadeia hidrocarbônica, em um mecanismo similar à polimerização, com o monômero $\left(* \mathrm{CH}_{2}\right)$ se formando in situ, na superfície do catalisador. A primeira etapa é a adição de uma molécula de $\mathrm{CO}$ e posteriormente de $\mathrm{H}_{2}$. Finalmente, a adição de mais uma molécula de $\mathrm{H}_{2}$ provoca a liberação de uma molécula de água e formação de um grupo etil, com 2 átomos de carbono. O processo se repete com novas adições de $\mathrm{CO}$ e $\mathrm{H}_{2}$, crescendo o tamanho da cadeia. O processo termina com a dessorção da molécula de hidrocarboneto da superfície. Através do mecanismo é possível compreender como são formados os compostos oxigenados (alcoóis, ácidos carboxílicos, cetonas e aldeídos) e o porquê do predomínio de parafinas lineares. 
No processo F-T ocorre a geração de hidrocarbonetos com ligações saturadas e insaturadas. A reação de polimerização é fortemente exotérmica, como mostra a Equação 6:

$\mathrm{n} \mathrm{CO}+2 \mathrm{n} \mathrm{H}_{2} \rightarrow-\left(\mathrm{CH}_{2}\right)_{\mathrm{n}}{ }^{-}+\mathrm{n} \mathrm{H}_{2} \mathrm{O} \quad \Delta \mathrm{H}=-167,4 \mathrm{~kJ} / \mathrm{mol}$

Normalmente, em processos GTL, os produtos desejados são parafinas, olefinas e alcoóis. Os produtos indesejados são aldeídos, cetonas, ácidos, ésteres e carbono (coque). A representação das reações é mostrada a seguir: ${ }^{8,37}$

\section{Produtos desejados}

Parafinas

Olefinas

$$
n \mathrm{CO}+(2 n+1) \mathrm{H}_{2} \rightarrow \mathrm{C}_{n} \mathrm{H}_{2 n+2}+n \mathrm{H}_{2} \mathrm{O}
$$

Alcoóis

$$
n \mathrm{CO}+2 n \mathrm{H}_{2} \rightarrow \mathrm{C}_{n} \mathrm{H}_{2 n}+n \mathrm{H}_{2} \mathrm{O} \quad \Delta \mathrm{H}=-41,3 \mathrm{~kJ} / \mathrm{mol}
$$

Metano

$$
n \mathrm{CO}+2 \mathrm{nH}_{2} \rightarrow \mathrm{C}_{n} \mathrm{H}_{2 n+1} \mathrm{OH}+(n-1) \mathrm{H}_{2} \mathrm{O}
$$

$$
\mathrm{CO}+3 \mathrm{H}_{2} \rightarrow \mathrm{CH}_{4}+\mathrm{H}_{2} \mathrm{O}
$$

\section{Produtos indesejados}

Reação de water-gas shift (WGS)

$$
\mathrm{CO}+\mathrm{H}_{2} \mathrm{O} \rightarrow \mathrm{CO}_{2}+\mathrm{H}_{2} \quad \Delta \mathrm{H}=-41,1 \mathrm{~kJ} / \mathrm{mol}
$$

Deposição do coque

Reação de Boudouard

$$
\mathrm{H}_{2}+\mathrm{CO} \rightarrow \mathrm{C}+\mathrm{H}_{2} \mathrm{O}
$$

$$
\mathrm{CO}+\mathrm{CO} \rightarrow \mathrm{C}+\mathrm{CO}_{2}
$$

A reação 11, de WGS, é uma importante reação paralela, minimizando a produção de água e aumentando a produção de $\mathrm{CO}_{2}$. A água é o subproduto mais indesejado da síntese F-T, podendo afetar negativamente o desempenho industrial dos catalisadores (conversão, seletividade e estabilidade).$^{32} \mathrm{Em}$ termos cinéticos, acredita-se que a etapa determinante da taxa é a formação do monômero $\left(* \mathrm{CH}_{2}\right)$ na superfície do catalisador. ${ }^{38} \mathrm{~A}$ taxa de consumo do $\mathrm{CO}$ é representada pela soma da taxa de formação dos compostos orgânicos com a taxa de formação de $\mathrm{CO}_{2}$.

Considerando-se a reação genérica 7, os tipos de hidrocarbonetos formados seguem a clássica distribuição de Anderson-Schulz-Flory (ASF) ${ }^{14}$ que relaciona a fração mássica do hidrocarboneto com $n$ átomos de carbono na molécula $\left(\mathrm{W}_{\mathrm{n}}\right)$ com a probabilidade das moléculas de hidrocarbonetos continuarem a reagir para formar moléculas maiores $(\alpha)$, ou seja, um fator de crescimento da cadeia:

$$
\frac{W_{n}}{n}=(1-\alpha)^{2} \cdot \alpha^{(n-1)}
$$

Vale destacar que as especificações do catalisador e condições operacionais (temperatura, razão $\mathrm{CO} / \mathrm{H}_{2}$, pressão) regem a composição dos produtos.

\section{Catalisadores de Fischer-Tropsch}

Os catalisadores mais utilizados na síntese F-T são os metais cobalto e ferro, principalmente por razões econômicas (custo baixo), embora níquel e rutênio também possam ser utilizados. Em relação aos suportes, os mais citados na literatura são as aluminas, sílica, zeólita ZSM-5, zeólita L, hidrocalcita, peneiras moleculares mesoporosas do tipo HMS, MCM-41 e Al-MCM-41.

Os catalisadores à base de cobalto são a melhor escolha para a síntese F-T. Possuem uma melhor relação custo/conversão do CO, favorecem a formação de $\mathrm{C}_{5}{ }^{+}$e têm uma maior resistência à desativação. A reação WGS (11) é insignificante, formando quantidades mínimas de dióxido de carbono (minimizando a perda de uma fonte de carbono) e produzindo menos água. É o catalisador mais adequado para gás de síntese com alta relação $\mathrm{H}_{2} / \mathrm{CO}$, típica quando a fonte de carbono é o gás natural, caso das aplicações offshore. ${ }^{39}$

A desativação do catalisador de cobalto normalmente é resultante da oxidação do cobalto metálico, migração do metal para a rede do suporte, resultando na formação de compostos inativos (ex: aluminato de cobalto), agregação e crescimento de cobalto metálico na superfície do catalisador e perda de cobalto devido ao atrito (especialmente para reator trifásico de lama). A presença de água com alta pressão de vapor acelera a desativação do catalisador de cobalto suportado em $\mathrm{Al}_{2} \mathrm{O}_{3}$, devido à formação de óxidos. ${ }^{40}$

Os catalisadores à base de ferro têm atividade significante na reação WGS (11). A temperatura de operação influencia no equilíbrio da reação e na pressão parcial de água, consequentemente altera a taxa de conversão de CO. Em temperaturas menores a reação WGS apresenta pequenas conversões e baixa pressão parcial de água. À alta temperatura a pressão parcial de água aumenta a taxa da reação de WGS até cerca de 50\% de conversão de CO. Neste nível de conversão, a pressão parcial de $\mathrm{H}_{2}$ é baixa o suficiente para que a taxa da síntese F-T se torne dependente da produção de $\mathrm{H}_{2}$ pela reação de WGS. O uso de ferro como catalisador é indicado para uma baixa relação $\mathrm{H}_{2}$ / $\mathrm{CO}$, caso do uso do carvão como fonte de carbono. ${ }^{39}$

\section{Promotores}

Para obter um melhor desempenho dos catalisadores na síntese de F-T, faz-se uso de promotores - elementos que influenciam a seletividade e atividade do catalisador. Tipicamente, o catalisador à base de ferro contém pequenas quantidades de potássio ${ }^{41}$ e outros metais, como magnésio, cálcio, zinco, cobre e manganês. ${ }^{42}$ Gallegos et al.${ }^{43}$ relataram que a adição de magnésio ao catalisador $\mathrm{Fe} / \mathrm{SiO}_{2}$ aumentou a conversão total, a seletividade para olefinas e suprimiu a formação de metano. Já Pour et al. ${ }^{42}$ mostraram que o uso de cálcio, magnésio e lantânio como promotores do catalisador $\mathrm{Fe} / \mathrm{SiO}_{2}$ aumenta a basicidade e, em consequência, a atividade das reações de WGS e F-T, influenciando as etapas de formação de $\mathrm{CO}_{2}$ e $\mathrm{H}_{2} \mathrm{O}$ durante a reação de F-T, que ocorre basicamente com a reação de oxigênio adsorvido $\left(\mathrm{O}^{*}\right)$ com hidrogênio $\left(\mathrm{H}^{*}\right)$ ou monóxido de carbono $\left(\mathrm{CO}^{*}\right)$. Como resultado final, há maior produção de $\mathrm{CO}_{2}$ e menor produção de água. Segundo Wan et al. ${ }^{44} \mathrm{O}$ cobre aumenta a dispersão do $\mathrm{Fe}_{2} \mathrm{O}_{3}$, promovendo a redução do $\mathrm{H}_{2}$, mas suprimindo severamente a adsorção de $\mathrm{CO}$ e a carburização. Já o potássio retarda severamente a redução e suprime a adsorção de $\mathrm{H}_{2}$, facilitando a adsorção de $\mathrm{CO}$ e promovendo a carburização. Como resultado, o cobre decresce a atividade inicial das reações de F-T e WGS, mas aumenta sua estabilidade. Os dois metais, em conjunto, aumentam a atividade das duas reações e geram uma excelente estabilidade ao catalisador. Já a seletividade para hidrocarbonetos leves e metano é aumentada com a adição de $\mathrm{Cu}$, enquanto a seletividade para hidrocarbonetos pesados diminui, resultado oposto à adição com K. Magnésio e tório também podem ser utilizados como promotores estruturais, com a finalidade de estabilizar cristais do catalisador e aumentar a resistência estrutural dos mesmos nos reatores. ${ }^{38}$

\section{Reatores utilizados na síntese de Fischer-Tropsch}

As tecnologias desenvolvidas para a síntese F-T estão baseadas nos estudos de reatores químicos mais eficientes. Existem três tipos de reatores comercialmente utilizados: de leito fluidizado, de leito de lama (slurry reactor) e multitubular de leito fixo, conforme mostra a Figura 7. Segundo Neathery et al., ${ }^{45}$ o reator de leito de lama com concentração de catalisador de 15 a $20 \%$ é o mais utilizado.

Os reatores de leito fixo e de lama são utilizados para operar nos processos a baixas temperaturas. Apresentam escoamento 


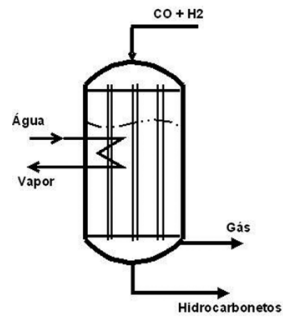

Reator Leito Fixo
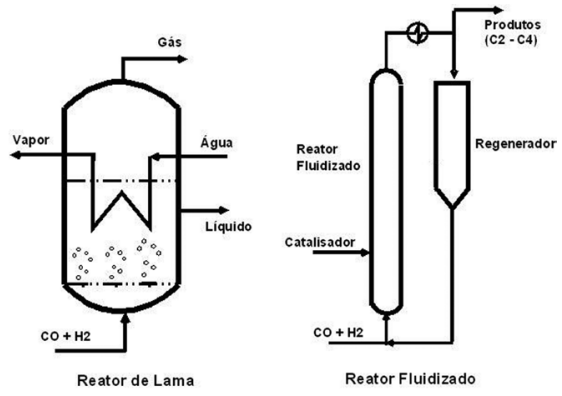

Figura 7. Tipos de reatores usados na síntese de Fischer-Tropsch

multifásico gás-líquido-sólido, no qual a fase gasosa consiste no gás de síntese, a fase sólida é o catalisador e a fase líquida o combustível. Os reatores de leito fixo são de simples operação e podem ser usados independente do estado físico dos produtos. Não há necessidade de separação do catalisador dos produtos após a reação. Este tipo de reator é apropriado na produção de cera. Suas desvantagens são o custo elevado para a construção, a grande queda de pressão gerada pelo alto fluxo de gás e o fato que o reciclo dos gases de saída exige uma etapa de compressão dos gases, elevando os custos. ${ }^{37}$ Para os reatores de lama as principais vantagens são: alta transferência de calor, ótimo controle de temperatura, fácil adição ou remoção de catalisador e simplicidade na montagem do reator.

Os reatores de leito fluidizado são utilizados para processos a altas temperaturas e operam apenas com as fases sólido (catalisador) e gás (reagentes e produtos). Apresentam uma excelente transferência de calor, um bom controle da temperatura e pouco problema de queda de pressão (proporcional à massa do catalisador). O sólido no leito fluidizado flui com viscosidade baixa, apresentando facilidade na remoção e adição. A principal desvantagem é que o produto deve ser gasoso nas condições da reação. Os hidrocarbonetos menos voláteis podem se acumular nas partículas do catalisador, aderindo em outras partículas e fazendo com que o leito fluidizado perca sua propriedade..$^{37,46}$

Novos estudos sobre reatores mais eficientes e que ocupem áreas menores estão sendo desenvolvidos para satisfazer as necessidades de operação em locais onde o espaço é limitado. Uma das tecnologias em estudo para resolver o problema de espaço limitado é a de microrreatores para a síntese de F-T, que será tratada em um tópico à parte desta revisão.

A síntese de F-T, além de ser uma reação de polimerização, é também uma reação de hidrogenação. Estão sendo estudadas tecnologias para melhorar a hidrogenação: umas delas é aplicação de membranas seletivas ao hidrogênio em reatores para síntese de F-T. A função da membrana é garantir o fluxo de hidrogênio que reage com o monóxido de carbono. Desta forma, é possível controlar a relação $\mathrm{H}_{2} / \mathrm{CO}$, fundamental para uma maior seletividade, tal como para gasolina de alta octanagem. ${ }^{47}$

Resumidamente, dependendo do tipo e da quantidade de produtos desejados, as seguintes regras gerais podem ser aplicadas na síntese F-T: ${ }^{15}$

- altas temperaturas $\left(300\right.$ a $\left.350^{\circ} \mathrm{C}\right)$, com catalisadores à base de ferro, levam à produção de gasolina sintética e outros produtos químicos, tais como olefinas e oxigenados;

- baixas temperaturas $\left(200 \mathrm{a} 250^{\circ} \mathrm{C}\right)$, com catalisadores à base de cobalto, conduzem à formação de ceras, que podem ser submetidas ao craqueamento para produzir naftas sintéticas, querosene ou diesel. Esta combinação tem sido uma tendência na síntese F-T, de modo a aumentar o rendimento de destilados médios, em especial o diesel; ${ }^{48}$
- a minimização da formação de metano é controlada mantendo-se a temperatura no reator abaixo de $400{ }^{\circ} \mathrm{C}$;

se a meta principal do processo for a maximização da produção de gasolina, Spath e Dayton ${ }^{49}$ recomendam utilizar catalisador de ferro, sob temperatura alta, num reator de leito fixo e, se o maior interesse recair sobre a produção de diesel, usar preferencialmente catalisador de cobalto, num reator de lama;

- as pressões aplicadas nos reatores normalmente variam de 10 a 40 bar.

\section{TECNOLOGIAS DE REFINO DOS PRODUTOS DA REAÇÃO F-T}

\section{Tratamento dos produtos de topo}

A corrente que sai do topo do reator (vide Figura 1), conhecida no jargão industrial como tailgas ou off-gas, é composta predominantemente por $\mathrm{CO}$ e $\mathrm{H}_{2}$ (não convertidos), $\mathrm{CO}_{2}$ e hidrocarbonetos leves formados na reação de F-T..$^{50}$ Tal mistura tem poder calorífico relativamente alto e pode ser usado diretamente como combustível em caldeiras a vapor para geração de energia térmica e/ou elétrica, sendo este seu principal uso. Outra alternativa é a reforma térmica, admitindo-se gás natural no processo, gerando-se mais $\mathrm{CO} \mathrm{e} \mathrm{H}_{2}$, que podem ser separados e reciclados para o reator de síntese. Nesse caso, os gases quentes do processo de reforma, com poder calorífico mais baixo, podem acionar turbinas a gás, gerando energia elétrica e, posteriormente, vapor de média pressão. ${ }^{51}$

A recuperação de $\mathrm{CO}$ e $\mathrm{H}_{2}$ da corrente de gás de topo pode ser feita mediante o uso de um ou mais dentre os seguintes processos: resfriamento da corrente gasosa seguido de uma separação flash para remoção de água como condensado, ${ }^{52,53}$ remoção de $\mathrm{H}_{2} \mathrm{~S}$ por redução a enxofre (processo Claus) ou por escoamento num leito fixo de $\mathrm{ZnO}^{54}$ ou de esponja de ferro; absorção do $\mathrm{CO}_{2}$ em soluções de aminas alifáticas, ${ }^{55}$ carbonato de potássio ou por adsorção usando zeólitas ou peneiras moleculares; recuperação de água para reuso usando membrana cerâmica, aumentando o teor de $\mathrm{CO}$ e $\mathrm{H}_{2}$ no gás. ${ }^{56}$

\section{Tratamento dos produtos de fundo}

A corrente de fundo do reator de F-T é conhecida como "óleo cru sintético" (syncrude), cuja separação e melhoramentos são bastante similares aos processos usados no processamento primário e nas refinarias de petróleo. Conforme mostrado na Figura 1, o fracionamento dessa corrente normalmente começa pela separação da água (e compostos oxigenados nela dissolvidos) da mistura complexa de hidrocarbonetos, a qual contém partículas de catalisador como impurezas indesejáveis. ${ }^{57}$ Essa etapa inicia efetivamente o processo de refino dos produtos da síntese de F-T, separando-se a água e outros compostos voláteis por stripping ou por destilaçãoflash, condensando-se posteriormente a água e gerando-se duas novas correntes: ${ }^{52}$ a primeira contendo hidrocarbonetos leves - que pode ser separada por destilação fracionada ou ser submetida a um melhoramento (upgrade) mediante o uso de técnicas como isomerização, alquilação e hidrogenação, e a segunda contendo as frações pesadas - que deve ser separada em seus principais compostos e passar por um processo de melhoramento, para produzir combustíveis comerciais ou naftas para uso petroquímico. ${ }^{57}$

Segundo Weick e Nimmo, ${ }^{52}$ a geração de água na síntese de F-T pela tecnologia GTL é da ordem de $1,1 \mathrm{~m}^{3}$ de água por $\mathrm{m}^{3}$ de óleo cru sintético. A prática da integração mássica é atualmente uma condição primordial para a viabilização dos processos de conversão de materiais que usam a síntese F-T. ${ }^{11}$ Portanto, a água gerada nos processos deve ser tratada para fins de reuso na planta, destacando-se as operações de resfriamento e geração de vapor..$^{52}$ 
A destilação fracionada é a operação unitária mais aplicada na separação dos hidrocarbonetos da fração pesada oriunda da síntese de F-T, na qual são separados os produtos leves (de cuja corrente é produzido um gás liquefeito semelhante ao GLP e naftas leves, com cadeias carbônicas variando de $\mathrm{C}_{5} \mathrm{a} \mathrm{C}_{9}$ ), os componentes intermediários (hidrocarbonetos líquidos com cadeias carbônicas na faixa $\mathrm{C}_{10}$ a $\mathrm{C}_{23}$ ) e as frações pesadas (parafinas e ceras, $\mathrm{C}_{23+}$ ). ${ }^{57}$ Os compostos mais pesados e, a depender da natureza da planta GTL, algumas frações intermediárias, são submetidos a processos de melhoramento, visando o aumento do rendimento em determinado tipo de combustível e tornar os produtos da síntese úteis para comercialização, semelhantes aos derivados de petróleo (gasolina, diesel, querosene de aviação etc.). ${ }^{52}$ Como exemplo de processos de melhoramento, podem-se citar o hidrocraqueamento (processo de alta seletividade para a produção de combustíveis que converte hidrocarbonetos pesados em hidrocarbonetos leves, na faixa de $\mathrm{C}_{4}$ a $\mathrm{C}_{12}$ ), ${ }^{58}$ a isomerização (por exemplo, a conversão de butano a isobutano) e a alquilação (por exemplo, a conversão de butano a isobutano). Esses processos são seguidos de novas etapas de fracionamento dos produtos gerados: gases, líquidos e sólidos ou semissólidos. ${ }^{7}$

\section{Separação do catalisador}

Um problema comum advindo do uso de catalisadores, em especial nos reatores de leito de lama, é a formação de finos (com diâmetros na faixa de 0,1 a $100 \mu \mathrm{m}),{ }^{33}$ devido ao atrito entre partículas do material catalítico durante a operação do reator, as quais ficam dispersas nos produtos da reação. Em alguns processos os finos são reciclados, de modo a se manter a quantidade de catalisador no reator e condicionar o produto para o hidrocraqueamento, cujo processo restringe o teor de partículas de catalisador de ferro ao máximo de 2 ppm. ${ }^{45}$ Portanto, uma separação sólido-líquido compatível com as características da mistura torna-se indispensável. ${ }^{59}$

De acordo com Biales et al. ${ }^{33}$ os teores residuais aceitáveis de catalisador nas ceras são de até $0,1 \%$ (em massa). Dentre os produtos da síntese, as parafinas e ceras são os materiais que mais incorporam os finos de catalisador, complicando mais ainda a separação. Os principais processos de separação dos finos são: sedimentação, separação centrífuga (usando hidrociclone), filtração sob pressão, extração líquido-líquido convencional ou supercrítica, separação magnética de alta intensidade ou técnicas combinadas. ${ }^{7,45,59-61}$

\section{VIABILIDADE TÉCNICA, ECONÔMICA E AMBIENTAL DA TECNOLOGIA GTL}

\section{Viabilidade técnica}

Desde a descoberta da síntese F-T em 1923, diversas pesquisas foram desenvolvidas envolvendo rotas alternativas em relação à proposta inicial, cujo resultado global é uma tecnologia madura, capaz de produzir combustíveis a partir do carvão mineral, do gás natural ou da biomassa em escala comercial, com viabilidade técnica comprovada.

A tecnologia GTL apresenta algumas vantagens em relação à produção de hidrocarbonetos derivados do petróleo, devido à sua capacidade de produzir diesel de alta cetanagem (70-80), dado o alto rendimento em hidrocarbonetos lineares, proporcionando desempenho superior para os motores. Outro aspecto relevante é a especialidade da tecnologia GTL no tocante à produção de destilados médios (combustível de aviação, querosene e diesel), gerando de 65 a $85 \%$ de produtos classificados como destilados leves, contra cerca de $40 \%$ produzidos no fracionamento do petróleo. Além disso, a qualidade dos lubrificantes produzidos por GTL é bastante superior à dos derivados de petróleo. ${ }^{62}$ Logo, pode substituir parcialmente o petróleo como principal matéria-prima para a produção de combustíveis.

Para a análise completa de viabilidade de uma planta GTL é imprescindível levar em consideração as variáveis econômicas e ambientais, discutidas nos itens seguintes.

\section{Aspectos econômicos}

A análise de viabilidade econômica da tecnologia GTL deve ser feita em relação à principal tecnologia concorrente, que é o refino de petróleo. Assim, o preço do barril de petróleo tem sido até agora o fator determinante do sucesso de um empreendimento voltado à

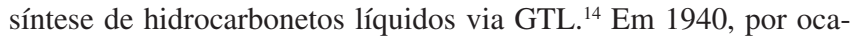
sião da II Guerra Mundial, a Alemanha produziu cerca de 600.000 t/ano de combustíveis líquidos a partir do gás de síntese oriundo da gaseificação do carvão, visando suprir as demandas internas e contornar a escassez gerada pelas tensões que prejudicam o comércio internacional em tempos de guerra. Outro fato que ilustra bem a concorrência da tecnologia GTL com o refino do petróleo foi o que aconteceu com uma planta GTL na Nova Zelândia, a qual foi construída no período da crise mundial do petróleo na década de 1970. Essa planta teve pleno sucesso durante a crise, mas foi fechada assim que a oferta de petróleo no mercado internacional foi regularizada, baixando o preço do barril..$^{15}$

Comparando-se as receitas de uma refinaria de petróleo e de uma planta GTL, pode-se concluir que, na primeira, independente dos valores pagos pelas matérias-primas, seu processo acompanha os preços do petróleo no mercado internacional.

A análise econômica de uma planta GTL não se restringe aos custos de equipamentos e construção, devendo também levar em consideração o tempo demandado para a construção de uma planta GTL, que pode durar até 4 anos. Além disso, é importante salientar que os custos OSBL (outside battery limits) são muito importantes, podendo chegar a 30\% do investimento total de uma planta GTL. Estes custos incluem investimentos na unidade de processamento de gás natural (UPGN), plantas de produção de eletricidade e tratamento de água, sistema de resfriamento de água e de estocagem de produtos. Assim, dependendo da localização da planta, os investimentos podem variar muito. Se a mesma for localizada junto a plantas GNL ou refinarias, poderá compartilhar os ativos OSBL, reduzindo significativamente os investimentos. Almeida et al. ${ }^{63}$ destacam que os custos de uma planta GTL se distribuem tipicamente de forma tal que a produção do gás de síntese apresenta um custo de $33 \%$; a conversão do gás de síntese $18 \%$; custos de operação e manutenção $23 \%$ e aquisição da matéria-prima $21 \%$. Tal divisão pode variar dependendo dos aspectos tecnológicos a serem usados em cada planta.

Segundo Weick e Nimmo, ${ }^{52}$ diversas variáveis afetam a lucratividade de uma planta GTL, tais como a capacidade da planta, custo de capital e preço do gás, além dos custos operacionais e de transporte. Dados relativos à tecnologia Syntroleum ${ }^{\circledR}$ (Tulsa, EUA), com base no óleo cru sintético, indicam a ordem de grandeza dos investimentos e custos operacionais com incerteza de $\pm 30 \%$, a saber: custo de capital da planta: US\$ 25.000/bbl (US\$ 157.250/m³) de capacidade diária; custo operacional: US\$ 5,00/barril (US\$ $31,50 / \mathrm{m}^{3}$ ).

Essa estimativa diverge dos dados da Shell baseados na planta instalada no Qatar, cuja capacidade de produção é de $140.000 \mathrm{bbl} / \mathrm{d}$, com investimentos de US\$12 a 18 bilhões, na qual o custo unitário de capital varia de US\$ 86.000 a US\$ 129.000 por barril produzido diariamente. ${ }^{14}$ Shen et al. ${ }^{64}$ tomando por base o preço do gás natural estipulado em US $\$ 0,50$ por milhão de Btu e o preço do petróleo bruto de US\$17,00/bbl, apresentam os custos de produção por barril de óleo processado (sintético no caso do GTL) representados na Tabela 1.

Sob essa base de cálculo, a tecnologia GTL é uma alternativa vantajosa em relação ao refino de petróleo convencional. Entretanto, se o preço do gás natural aumentar e o do petróleo diminuir, os nú- 
Tabela 1. Custos de produção por barril de óleo processado (sintético no caso GTL) $)^{64}$

\begin{tabular}{lcc}
\hline Item & \multicolumn{2}{c}{ US\$/barril processado } \\
\cline { 2 - 3 } & GTL & Refino de petróleo \\
\hline Gás natural & 4,00 & - \\
Óleo cru & - & 17,00 \\
Custo operacional & 3,00 & 2,50 \\
Capital recuperado & 12,00 & 6,50 \\
Custo total de produção & 19,00 & 26,00 \\
\hline
\end{tabular}

meros poderão ser bastante desfavoráveis à tecnologia GTL. Nesse contexto, Bao et al. ${ }^{14}$ apresentam uma análise econômica mais atual, inclusive simulando diferentes cenários com a adoção de integração mássica e energética na planta. O estudo foi desenvolvido com base nos seguintes dados: capacidade de processamento da planta de $3,29 \times 10^{9} \mathrm{Nm}^{3} / \mathrm{d}$ de gás natural; produção estimada de óleo sintético: $18.760 \mathrm{~m}^{3} / \mathrm{d}$; preço do gás natural: US $\$(0,18$ a 0,28$) / \mathrm{m}^{3}$; retorno do investimento (ROI): 7,4 a 19,4\% a.a.; custo de produção sem integração energética: US\$ 58,05/(bbl.d); custo de produção com integração energética: US\$ 48,76/(bbl.d). Tomando-se por base a média de preço do gás natural da US Energy Information Administration de março a agosto de 2010, chega-se ao valor US\$ $0,15 / \mathrm{m}^{3}$. Assim, mantendo-se os demais indicadores usados por Bao et al. ${ }^{14}$ os resultados seriam ainda mais favoráveis à tecnologia GTL. Esses mesmos autores fizeram ainda uma análise do ponto de equilíbrio (break-even-point) da tecnologia GTL, que, nas condições correntes de mercado no ano de 2008, foi estimado em $9.062 \mathrm{~m}^{3} / \mathrm{d}$, que seria a capacidade mínima de produção de sintético cru que torna o negócio lucrativo. Esse valor é coerente com a capacidade mínima de produção de Shen et al. ${ }^{64}$ de $9.539 \mathrm{~m}^{3} /$ d. Evidentemente, a redução do preço do gás e o aumento dos preços dos produtos acabados aumentarão a lucratividade da planta GTL. O ponto de equilíbrio da tecnologia GTL, sem sequestro de carbono, em termos do preço do destilado médio, segundo van Vliet et al. ${ }^{65}$ é de US\$ 36,00/bbl (US\$ $226,44 / \mathrm{m}^{3}$ ), relativo ao preço do diesel convencional. Esta é uma das principais razões das companhias de petróleo estarem investindo na tecnologia GTL nos dias atuais.

De acordo com estimativas da US Federal Aviation Administration, ${ }^{66}$ a produção mundial de combustíveis através da tecnologia GTL evoluirá no seguinte ritmo: $15.900 \mathrm{~m}^{3} / \mathrm{d} \mathrm{em} \mathrm{2005;} 47.690 \mathrm{~m}^{3} / \mathrm{d}$ em 2015; $413.400 \mathrm{~m}^{3} / \mathrm{d}$ em 2030. Por outro lado, Arzamendi et al. ${ }^{67}$ estimam uma produção de $39.740 \mathrm{~m}^{3} / \mathrm{d}$ para o ano 2020 .

A tecnologia GTL tem um grande impacto na dinâmica dos mercados mundiais de óleo e gás, visto que representa o limite máximo para os preços do petróleo a longo prazo. Caso este preço se sustente acima do custo do GTL, novas empresas serão atraídas para entrar nesse negócio, permitindo a exploração de reservas remotas de gás com as tecnologias de transporte tradicionais. Com relação ao mercado de gás, o GTL representa um limite mínimo, uma vez que as empresas que comercializam o gás podem enxergar o GTL como mais uma possibilidade de valorização do seu produto. ${ }^{10}$

\section{Vantagens ambientais da tecnologia GTL}

A síntese F-T é apontada como uma tecnologia ambientalmente amigável em relação ao refino de petróleo, pelas seguintes razões:

- o teor de enxofre no diesel sintético produzido por tal tecnologia é muito pequeno, inferior a $15 \mathrm{ppm},{ }^{64}$ podendo diminuir bastante o tamanho da unidade de dessulfurização;

- é possível a produção de outros produtos, como gás liquefeito sintético, naftas petroquímicas, lubrificantes e ceras com excelentes qualidades técnicas e ambientais, destacando seus baixíssimos teores de enxofre, ${ }^{68}$

viabilização de uso e valoração econômica das reservas de gás situadas em áreas remotas (stranded gas). Uma reserva pode ser considerada remota quando: há um excesso de oferta potencial para o domínio do mercado viável; sua distância do mercado potencial é tal que os custos de transporte não são competitivos; o campo está em um país sem litoral com um pequeno mercado de gás e com uma grande distância da costa, dificultando a construção de um terminal de gás natural liquefeito (GNL) para a sua exportação e quando o campo é muito pequeno para justificar o investimento em infraestrutura, em uma escala econômica, para explorá-lo; ${ }^{69}$

- pode ser considerada uma maneira indireta de se colocar gás natural, carvão ou biomassa no tanque dos automóveis na forma de combustíveis líquidos limpos; ${ }^{66}$

- a geração de $\mathrm{CO}_{2}$ em fontes puntuais (na planta industrial) permite a captura e o sequestro permanente do gás, reduzindo as taxas líquidas de emissão e, consequentemente, o potencial de efeito estufa da tecnologia GTL;

- o combustível produzido tem menor teor de aromáticos e menor geração de material particulado (fuligem) durante a combustão, o que representa um ganho em termos de segurança e saúde ocupacional; ${ }^{62}$

- $\quad$ segundo Wu et al. ${ }^{70}$ o uso do diesel GTL gera menos poluentes atmosféricos e contaminantes ambientais que o uso do diesel convencional, conforme mostra a Tabela 2;

- os combustíveis são mais biodegradáveis que os derivados de petróleo (60\% de degradação em 28 dias, em condições de anaerobiose ${ }^{62}$

Tabela 2. Redução da emissão de poluentes no uso do diesel GTL

\begin{tabular}{lcc}
\hline Material & \% Redução & Observação \\
\hline Aromáticos & 94,9 & Diesel de petróleo: 27,7\%; diesel GTL: 1,4\% \\
Poliaromáticos & 93,5 & Diesel de petróleo: 6,2\%; diesel GTL: 0,4\% \\
CO & 16,6 & \\
NOx & 23,7 & \\
Particulados & 27,6 & \\
\hline
\end{tabular}

Um dos resíduos da síntese de F-T que requer grande atenção é o dióxido de carbono, por razões associadas ao fenômeno de aquecimento global. A Tabela 3 apresenta uma comparação das taxas de geração de $\mathrm{CO}_{2}$ nos processos mais utilizados baseados na síntese de F-T.

Tabela 3. Fatores de emissão de dióxido de carbono em processos baseados na síntese F-T

\begin{tabular}{lcc}
\hline Processo & Geração $\left(\mathrm{tCO}_{2} / \mathrm{bbl}\right)$ & Ref. \\
\hline Diesel CTL $^{(*)}$ & 0,80 & 72 \\
Diesel GTL & \\
Diesel convencional & 0,13 & $15 ; 70 ; 71$ \\
Diesel CTL & \\
Diesel CTL & 0,50 & \\
Diesel GTL & \\
Diesel GTL & 0,98 & 0,46 \\
\hline
\end{tabular}

(*) sem captura e sequestro de carbono; (**) com captura e sequestro de carbono. Dados convertidos usando-se os poderes caloríficos inferiores do diesel convencional e do diesel F-T, respectivamente, iguais a 35,7 e $33,7 \mathrm{MJ} / \mathrm{L}^{15}$ massa específica do diesel convencional e do diesel F-T, respectivamente, iguais a 0,83 e $0,78 \mathrm{~kg} / \mathrm{L}$. 
Conclui-se que há uma divergência entre os valores dos fatores de emissão entre as fontes bibliográficas consultadas. Porém, nota-se que as emissões de $\mathrm{CO}_{2}$ na combustão do diesel produzido pelo processo CTL são superiores às do processo GTL, em qualquer situação. Já a emissão pelo diesel convencional normalmente é maior que o processo GTL, sendo similar no caso de não haver captura e sequestro de dióxido de carbono. Esta captura é a medida mais recomendável para assegurar a viabilidade ambiental das tecnologias GTL e CTL..$^{15,71,72}$ Estudos realizados pelo NETL/DOE/EUA ${ }^{73,74}$ apontam custos ligados à captura e sequestro de carbono na faixa de US\$17,67 a 42,40 por milhão de $\mathrm{m}^{3}$ de $\mathrm{CO}_{2}$. Nas condições de sequestro dos projetos mencionados, essa alternativa seria viável para o preço do barril de petróleo na faixa de US\$35,00 a 40,00. Utilizando outra base de cálculo, van Vliet et al. ${ }^{65}$ estimaram os custos da captura e do sequestro do $\mathrm{CO}_{2}$ em $15 € /$ t. Os custos da captura e sequestro do gás carbônico dependem de uma série de fatores, destacando-se a distância da fonte ao ponto de descarte e a pressão necessária para injeção.

\section{APLICAÇÕES OFFSHORE E A TECNOLOGIA MILICANAIS}

Dados de 2009 indicam que as reservas mundiais provadas de gás natural são de cerca de $1,69 \times 10^{11}$ toneladas de óleo equivalente (toe), enquanto a de petróleo é de cerca de $1,82 \times 10^{11}$ toe, isto é, são similares. ${ }^{75}$ No entanto, grande parte dessas reservas está localizada em áreas remotas, cujo transporte via gasodutos seria oneroso e a produção só se torna viável se o gás for liquefeito (GNL) ou se o mesmo for transformado em líquido via síntese de F-T. ${ }^{66}$ Segundo Zamalloa, ${ }^{10}$ o principal nicho de mercado para a tecnologia GTL deve ser a valorização do gás produzido em áreas remotas que, em teoria, apresenta baixo valor comercial.

Das reservas remotas, destaca-se a parcela do gás natural associado produzido juntamente com a produção em áreas marítimas de petróleo. Neste caso, é interessante construir uma planta GTL offshore, mais compacta e com capacidade flexível. Existem duas possibilidades para isto: utilizar balsas, destinadas a operações em águas calmas; ou em plataformas FPSO (Floating, Production, Storage and Offloading), destinadas às operações em condições severas climáticas e no mar. Uma das vantagens desta planta é a possibilidade de remanejá-la para outro campo produtor de petróleo quando a produção do campo onde a planta opera está em declínio e não permite que o seu funcionamento seja economicamente viável. ${ }^{3}$ Também podem ser utilizadas quando não há infraestrutura de processamento nem de transporte do gás, a exemplo da Nigéria, que tem queimado diariamente centenas de milhões de $\mathrm{m}^{3}$ de gás. ${ }^{72} \mathrm{~A}$ partir do momento que os compostos líquidos são produzidos, é possível realizar o seu transporte, de maneira convencional, separados ou misturados ao petróleo, valendo-se da infraestrutura já existente para o petróleo. ${ }^{8}$

Outra utilidade de uma planta GTL offshore é minimizar a queima de gás natural em testes de longa duração em novos poços. Hoje em dia a Agência Nacional de Petróleo (ANP) só permite a realização destes testes se houver um destino para o gás natural que não seja o lançamento in natura ou a queima, isto é, existem fortes restrições ambientais para estes destinos.

Embora o aproveitamento do gás natural remoto através de uma planta GTL convencional seja interessante, algumas limitações, tais como o alto custo de investimento, fazem com que a exploração seja lucrativa apenas quando se trata de campos muito grandes..$^{67,69}$

Neste contexto, a tecnologia microcanais pode ajudar a superar algumas dessas limitações, miniaturizando equipamentos e tubulações, de forma a diminuir o tamanho da planta e permitir uma aplicação offshore. Consiste na utilização de aparatos contendo canais abertos paralelos com pelo menos uma dimensão (ex: diâmetro) abaixo de 1 $\mathrm{mm}$, onde escoam fluidos, em geral em regime laminar. As reações ocorrem dentro destes canais, com uma altíssima relação área/volume (de 10.000 a $50.000 \mathrm{~m}^{2} / \mathrm{m}^{3}$, contra $100 \mathrm{~m}^{2} / \mathrm{m}^{3}$ de reatores convencionais). ${ }^{76}$ Dessa forma, tanto a área de troca térmica quanto o coeficiente de transferência de calor são sensivelmente aumentados (em pelo menos uma ordem de magnitude), resultando numa intensificação de processos (process integration - PI), tanto em termos de taxas de transferência de calor e massa quanto de taxas de reação.

A tecnologia microcanais tem vantagem ainda maior em reações altamente exotérmicas, como a síntese F-T, visto que, em reatores convencionais, a produtividade passa a ser limitada pela capacidade de remoção de calor. Com o maior controle de temperatura do aparato de microcanais, o reator consegue operar perto da condição isotérmica e evita-se a formação de pontos quentes, que podem gerar problemas de segurança e baixa seletividade para destilados médios, já que a probabilidade de crescimento da cadeia diminui com o aumento de temperatura ${ }^{48} \mathrm{O}$ tempo de residência é bem inferior nos reatores microcanais (ex: $0,2 \mathrm{~s}$, contra $10 \mathrm{~s}$ da tecnologia tradicional), o que também ajuda a obter uma seletividade maior para destilados médios e permite uma integração energética entre a síntese F-T e a geração de vapor. ${ }^{67,77}$ Outra característica desta tecnologia é a baixíssima queda de pressão gerada. Como resultado destas vantagens, a reação de reforma a vapor é acelerada cerca de 200 vezes e a síntese F-T de 10 a 15 vezes. ${ }^{78}$ Dessa forma, há um aumento da produtividade total da planta em cerca de 7 vezes. Outra característica desta tecnologia é sua baixa sensibilidade de movimento, necessária para aplicações offshore. Além disso, o consumo de água é inferior ao da reforma tradicional, como resultado da baixa razão vapor/fonte de cabono. ${ }^{63}$

Vale ressaltar que a maior parte dos projetos anunciados até hoje, que consideram o uso de plantas GTL offshore, utilizam o processo de reforma a vapor do metano para gerar o gás de síntese, com exceção das empresas Haldor Topsoe e Statoil, que utilizam a reforma autotérmica. Isto ocorre porque a reforma autotérmica necessita de uma unidade para a produção de oxigênio, o que encarece de maneira considerável sua implementação. ${ }^{3}$

\section{QUADRO ATUAL DAS TECNOLOGIAS GTL E CTL PELO MUNDO}

A Tabela 4 apresenta um resumo das plantas em funcionamento e das plantas previstas (até 2012) para a produção de líquidos por meio da síntese de F-T. Uma grande parte dos dados foi obtida no portal da National Energy Technology Laboratory (NETL), ${ }^{79}$ pertencente e operada delo Departamento de Energia Americano (DOE).

Conforme esperado, a Sasol é a empresa com maior número de plantas, quase todas à base de carvão, com a tecnologia Sasol Lurgi, com reatores F-T de leito fixo. A Sasol também tem plantas em conjunto com a Chevron, uma em operação no Catar e outra em construção na Nigéria, ambas baseadas na tecnologia Sasol Slurry Phase Distillate (SPD), com reatores F-T de leito de lama. A empresa Petro SA é uma estatal da África do Sul e usa reatores F-T de leito de lama. Já a empresa anglo-holandesa Shell possui duas plantas, uma operando e outra com previsão de startup ainda este ano, que será a planta com maior capacidade do mundo (140.000 bbl/dia), ambas com o uso da tecnologia Shell Middle Distillate Synthesis (SMDS), à base de reatores F-T de leito fixo, voltadas à produção de destilados médios, principalmente querosene e solventes. A empresa americana Rentech possui duas plantas em fase de instalação, as primeiras dos EUA, ambas com a tecnologia E-Gas, da empresa americana ConocoPhillips, para gaseificação do carvão em reatores de leito de lama e tecnologia própria com reatores de leito de lama para síntese F-T. A planta de East Dubuque já opera para produzir amônia, mas sofrerá alteração para produzir também produtos F-T, além de 
Tabela 4. Plantas GTL e CTL mundiais em $2010^{79}$

\begin{tabular}{|c|c|c|c|c|c|c|}
\hline Local & Empresa & $\begin{array}{l}\text { Nome } \\
\text { Planta }\end{array}$ & Tecnologia & $\begin{array}{c}\text { Status } \\
\text { (ano início) }\end{array}$ & Matéria-prima & $\begin{array}{l}\text { Produção GTL } \\
\text { (bbl/dia) }\end{array}$ \\
\hline Sasolburg, África do Sul & Sasol & $\begin{array}{l}\text { Sasol-I F-T } \\
\text { Syngas }\end{array}$ & $\begin{array}{l}\text { Sasol Lurgi } \\
\text { Fixed Bed }\end{array}$ & $\begin{array}{l}\text { em operação } \\
(1955)\end{array}$ & Carvão & 4.000 \\
\hline Secunda, África do Sul & Sasol & Sasol Synfuels & $\begin{array}{l}\text { Sasol Lurgi } \\
\text { Fixed Bed }\end{array}$ & $\begin{array}{l}\text { em operação } \\
\text { (1977) }\end{array}$ & Carvão & 124.000 \\
\hline Secunda, África do Sul & Sasol & $\begin{array}{c}\text { Gasification } \\
\text { East Plant }\end{array}$ & $\begin{array}{l}\text { Sasol Lurgi } \\
\text { Fixed Bed }\end{array}$ & $\begin{array}{l}\text { em operação } \\
\quad(1982)\end{array}$ & Carvão & \\
\hline Bintulu, Malásia & Shell & Bintulu & $\begin{array}{c}\text { Shell Gasification } \\
\text { Process }\end{array}$ & $\begin{array}{c}\text { em operação } \\
\text { (1993) }\end{array}$ & Gás Natural & 12.500 \\
\hline Mossel Bay, África do Sul & Petro SA/Statoil & Mossgas & Sasol Synthol & $\begin{array}{l}\text { em operação } \\
\text { (2004) }\end{array}$ & $\begin{array}{l}\text { Gás Natural } \\
\text { offshore }\end{array}$ & 36.000 \\
\hline Ras Laffan, Catar & Sasol/Chevron & Oryx GTL & Sasol SPD & $\begin{array}{l}\text { em operação } \\
\text { (2006) }\end{array}$ & Gás Natural & 34.000 \\
\hline Ras Laffan, Catar & Shell & Pearl GTL & $\begin{array}{l}\text { Shell Gasification } \\
\text { Process }\end{array}$ & $\begin{array}{c}\text { a operar } \\
\text { (final de 2010) }\end{array}$ & Gás Natural & 140.000 \\
\hline East Dubuque, IL, EUA & Rentech & $\begin{array}{l}\text { East Dubuque } \\
\text { Fischer Tropsch }\end{array}$ & $\begin{array}{c}\text { E-Gas } \\
\text { ConocoPhillips }\end{array}$ & a operar (2011) & Carvão & 2.700 \\
\hline Escravos, Nigeria & Sasol/Chevron & - & Sasol SPD & a operar (2012) & Gás Natural & 34.000 \\
\hline Adams County, MS, EUA & Rentech & $\begin{array}{c}\text { Rentech Strategic } \\
\text { Fuels }\end{array}$ & $\begin{array}{c}\text { E-Gas } \\
\text { ConocoPhillips }\end{array}$ & a operar (2012) & Carvão & 10.000 \\
\hline Burrup Penins, Austrália & Syntroleum & Sweetwater & Syntroleum & a operar (2012) & Gás natural & 10.000 \\
\hline
\end{tabular}

${ }^{a}$ Planta localizada no continente. O gás offshore é enviado por dutos

1000 t/dia de amônia. Outra empresa americana no ramo é a Syntroleum, que desenvolve tecnologia própria, à base de reforma autotérmica, e está instalando uma planta na Austrália.

Além das plantas mencionadas na Tabela 4, existem diversos projetos em planejamento. A Sasol está realizando estudos de viabilidade para duas grandes plantas CTL no oeste da China, destacando-se a planta na região de Ningxia Hui, uma joint venture com a empresa chinesa Shenhua Corporation para uma planta de 80.000 barris/dia. Existem ainda nove projetos de plantas GTL em vários estágios de planejamento e desenvolvimento até 2015 , sendo seis deles no Catar. ${ }^{80}$ A maior parte utiliza a reforma autotérmica, inclusive as plantas em construção da Sasol.

Vale ressaltar que, embora haja várias plantas GTL em operação e em construção no mundo, a capacidade total de todas elas gira em torno de 600.000 barris por dia, o que representa cerca de $3 \%$ do consumo total de óleo cru projetado para $2015 .{ }^{81}$ Isto significa que, por enquanto, a tecnologia GTL está longe de suprir totalmente a necessidade mundial de combustíveis e derivados de petróleo.

Em termos de plantas GTL offshore, algumas empresas se identificam como fabricantes, embora com tecnologias GTL convencionais (sem miniaturização), tais como a Metaprocess e a Statoil. Outras utilizam a tecnologia denominada Compact reformer, tais como a Davy Process Technology e Haldor Topsoe. Vale destacar que três empresas dominam a tecnologia microcanais: a americana Velocys $\mathrm{s}^{77,78}$ e as inglesas CompactGTL ${ }^{82}$ e Heatric. ${ }^{83}$ As duas primeiras têm interesse na produção de produtos F-T e syncrude, reduzindo a queima de gás, enquanto a Heatric tem como foco a produção de metanol. Embora não haja registro de plantas comerciais (apenas projetos pilotos) destas três empresas, a CompactGTL afirma que sua planta pode ter a capacidade de $159-795 \mathrm{~m}^{3} / \mathrm{dia}$, enquanto a Velocys afirma que seu reator possui mais de 900 microcanais, com capacidade de $1000 \mathrm{t} / \mathrm{dia}^{3}$ A empresa americana Rentech anunciou recentemente um acordo com a empresa Global Process Systems (Catar) para o desenvolvimento de tecnologia GTL offshore em plataformas FPSO, para plantas com capacidade de 2.500 a
$10.000 \mathrm{bbl} / \mathrm{dia}$, mas não esclarece se a tecnologia é microcanais. ${ }^{84}$ A empresa Davy Process Technology opera uma planta piloto com reformador compacto, com capacidade de $300 \mathrm{bbl} / \mathrm{dia}$, em Nikisti (Alasca, EUA), desde outubro de 2002. ${ }^{85}$

\section{DESAFIOS E PERSPECTIVAS DA TECNOLOGIA GTL NO BRASIL}

Segundo o Anuário Estatístico da ANP, ${ }^{86}$ as reservas totais de gás natural brasileiro totalizam 600 bilhões de $\mathrm{m}^{3}$. Destes, $82,1 \%$ se encontravam, ao fim de 2009, em reservatórios marítimos (offshore), liderados pelo Rio de Janeiro (57,4\% das reservas marítimas), Espírito Santo (18,6\%), São Paulo (12,6\%) e Bahia (7,0\%), enquanto todos os demais estados da Federação possuem os 5,5\% restantes. Percebe-se, então, o grande mercado que a tecnologia GTL offshore tem no país, especialmente na região Sudeste.

Além disto, o Brasil tem uma grande perspectiva de produção de petróleo e gás do pré-sal, camada que se estende desde o litoral de Santa Catarina até o Espírito Santo, numa faixa de $800 \mathrm{~km}$ ao longo da margem continental, com cerca de $200 \mathrm{~km}$ de largura. Distribuídas na bacia de Santos e Campos, essas rochas estão abaixo de uma camada de sal que pode chegar a $2.000 \mathrm{~m}$ de espessura, sob lâmina d'água de até $3.000 \mathrm{~m}$, com uma produção estimada para 2020 de 1,8 milhão de barris/dia, ${ }^{87}$ praticamente dobrando a quantidade produzida em 2009 de 2,0 milhões de barris/dia. ${ }^{75}$

As restrições ambientais para o lançamento in natura ou a queima, por parte da ANP, podem inviabilizar a exploração de poços de petróleo com gás natural associado, inclusive do pré-sal, que necessita de testes de longa duração e é uma reserva remota. Estudos comprovam que o limite de queima permitido pela ANP é muito inferior ao que deverá ser gerado na produção dos poços de petróleo do pré-sal. ${ }^{67} \mathrm{O}$ uso de plantas GTL offshore pode resolver este problema e tornar o processo viável, independente do preço do petróleo e derivados, já que a motivação econômica passa a ser a exploração do poço em si. Logo, a descoberta das reservas do pré-sal trouxe grandes perspec- 
tivas para aplicação da tecnologia GTL no Brasil, seja a tradicional, seja a offshore.

Novidades recentes no mercado brasileiro ocorreram em ternos de aquisição de plantas-piloto com tecnologia microcanais pela Petrobras, baseadas na reforma a vapor do metano. Uma delas é uma parceria com a empresa CompactGTL com capacidade de produção de 20 barris de syncrude/dia. A planta deverá ter sua partida ainda em 2010 e será testada pela empresa em terra (Polo de Atalaia, UN-SEAL, Aracaju - SE) antes de ser movida para uma instalação offshore. É projetada especificamente para atuar com gás associado de campos de petróleo em águas profundas ou ambientes remotos. A CompactGTL, através desta primeira planta no mundo, pretende continuar o desenvolvimento desta tecnologia e ter a primeira planta comercial em 2012. ${ }^{82}$ A outra parceria é com a empresa Velocys, junto com a Toyo Engineering e MODEC, para construção de uma planta integrada de 6 bbl/dia, a ser instalada em Fortaleza - CE, com um custo de US\$ 10 milhões, com previsão de envio ao Brasil no primeiro semestre de 2011. Os reatores serão confeccionados pela empresa japonesa Kobe Steel. ${ }^{78}$ Além desta planta, existem mais duas de 1 bbl/dia à base de biomassa na Áustria e nos EUA.

Embora as vantagens da tecnologia microcanais para aplicações offshore tornem o processo muito atraente, alguns desafios precisam ser cumpridos para a tecnologia ser difundida no Brasil. Ainda não existe nenhuma planta offshore em funcionamento no país e as tecnologias existentes ainda não foram aplicadas nas condições de operação específicas, o que significa que problemas aparecerão e precisarão ser contornados. Além disso, as experiências práticas existentes são restritas e as estimativas de investimentos podem estar subavaliadas. Por outro lado, não se conhecem as curvas de aprendizado e o potencial de ganho com a economia de escala, tornando difícil qualquer previsão de redução de custos para o futuro. Outro problema brasileiro é o fornecimento de gás natural. Embora o Brasil tenha grandes reservas de gás, sua produção não é suficiente para atender o consumo e existe uma dependência do gás natural da Bolívia. No entanto, o aproveitamento das reservas remotas nada tem a ver com este mercado e pode viabilizar a tecnologia GTL.

\section{CONCLUSÕES}

A síntese de Fischer-Tropsch se destaca como tecnologia limpa para produção de combustíveis líquidos limpos, devido aos baixos teores de contaminantes, principalmente o enxofre, além de outras vantagens ambientais ligadas à redução da poluição em comparação com a queima do diesel de petróleo.

A tecnologia GTL apresenta-se como uma alternativa viável nos casos em que o barril de petróleo tenha o seu preço elevado (a exemplo de situações de crise) ou se o preço do gás natural for suficientemente baixo ou até mesmo negativo (no caso em que há pagamento de royalties em relação ao volume de gás queimado).

Com o aumento das restrições ambientais no tocante às emissões de dióxido de carbono, devido ao efeito estufa, a queima de gás em testes de poços exploratórios ficará cada vez mais proibitiva, de modo que a tecnologia GTL com captura e sequestro de carbono tornar-se-á uma das alternativas mais indicadas para resolver esse tipo de problema.

Com a oscilação do mercado de petróleo, tornar-se-á imperativa a busca por fontes alternativas de energia. Nesse contexto, a exploração de gás natural de áreas remotas (stranded gas) ganhará destaque no cenário econômico e a tecnologia GTL apresenta-se atualmente como a principal alternativa para valoração econômica dessas reservas e viabilização da produção, em especial no Brasil, com grande quantidade dessas reservas, principalmente na camada do pré-sal.

\section{REFERÊNCIAS}

1. Maggio, G.; Cacciola, G.; Energy Policy 2009, 37, 4761.

2. Souza, M. M. V. M.; Tecnologia do Hidrogênio, $1^{\mathrm{a}}$ ed., Synergia: Rio de Janeiro, 2009.

3. Branco, D. A. C.; Dissertação de Mestrado, Universidade Federal do Rio de Janeiro, Brasil, 2008.

4. Liaquat, A. M.; Kalam, M. A.; Masjuki, H. H.; Jayed, M. H.; Atmos. Environ. 2010, 44, 3869.

5. Klingenberg, H.; Winneke, H.; Sci. Total Environ. 1990, 93, 95.

6. Dry, M. E.; Appl. Catal., A 2004, 276, 1.

7. Storch, H. H.; Anderson, R. B.; Hofer, L. J. E.; Hawk, C. O.; Anderson, H. C.; Golumbic, N.; Synthetic Liquid Fuels From Hydrogenation of Carbon Monoxide. Part 1. Review of Literature, Bureau of Mines/US Department of the Interior, 1948.

8. Steynberg, A.; Dry, M., eds.; Fischer-Tropsch Technology, Elsevier: Netherland, 2004.

9. Schulz, H.; Appl. Catal., A 1999, 186, 3.

10. Zamalloa, G. A. C.; Tese de Doutorado, Universidade de São Paulo, Brasil, 2004.

11. Rodrigues, R. C.; Bontempo, J. V.; $3^{\circ}$ Congresso Brasileiro de P\&D em Petróleo e Gás, Salvador, Brasil, 2005.

12. Santana, C. N.; Projeto Final de Curso, Escola de Química, Universidade Federal do Rio de Janeiro, 2006.

13. Sousa-Aguiar, E. F.; Appel, L. G.; Mota, C.; Catal. Today 2005, 101, 3.

14. Bao, B.; El-Halwagi, M. M.; Elbashir, N. O.; Fuel Process. Technol. 2010, 91, 703.

15. Sims, R.; Taylor, M.; Saddler, J.; From $1^{\text {st }}$ to $2^{\text {nd }}$ Generation Biofuel Technology, International Energy Agency, 2008.

16. Rostrup-Nielsen, J. R.; Catal. Today 2000, 63, 159.

17. Rostrup-Nielsen, J. R.; Sehested, J.; Norskov, J. K.; Advances in Catalysis 2002, 47, 65.

18. Dybkjaer, I.; Fuel Process. Technol. 1995, 42, 85.

19. Souza, M. M. V. M.; Schmal, M.; Appl. Catal., A 2005, 281, 19.

20. Rostrup-Nielsen, J. R.; Rostrup-Nielsen, T.; CATTECH 2002, 6, 150.

21. Bradford, M. C. J.; Vannice, M. A.; Catal. Rev. - Sci. Eng. 1999, 41, 1.

22. Teuner, S.; Hydrocarbon Processing 1985, 64, 106.

23. Udergaard, N. R.; Hansen, J-H. B.; Hanson, D. C.; Stal, J. A.; Oil Gas J. 1992, 90, 62 .

24. Gadalla, A. M.; Bower, B.; Chem. Eng. Sci. 1988, 43, 3049.

25. Peña, M. A.; Gómez, J. P.; Fierro, J. L. G.; Appl. Catal., A 1996, 144, 7.

26. Wilhelm, D. J.; Simbeck, D. R.; Karp, A. D.; Dickenson, R. L.; Fuel Process. Technol. 2001, 71, 139.

27. Aasberg-Petersen, K.; Christensen, T. S.; Nielsen, C. S.; Dybkjær, I.; Fuel Process. Technol. 2003, 83, 253.

28. Dicks, A. L.; J. Power Sources 1996, 61, 113.

29. Rezaiyan, J.; Cheremisinoff, N. P.; Gasification Technologies - A primer for engineers and scientists, CRC Press: Boca Raton, 2005.

30. Klass, D. L.; Biomass for renewable energy, fuels, and chemicals, Academic Press: London, 1998.

31. Higman, C.; van der Burgt, M.; Gasification, Elsevier: Burlington, 2003.

32. Dalai, A. K.; Davis, B. H.; Appl. Catal., A 2008, 348, 1.

33. Biales, J. M.; Wan, Y. D.; Kilpatrick, P. K.; Roberts, G. W.; Energy Fuels 1999, 13, 667.

34. Hackett, C.; Williams, R. B.; Durbin, T. D.; Evaluation of Conversion Technology Processes and Products, Integrated Waste Management Board: Sacramento, 2004.

35. Riedel, T.; Claeys, M.; Schulz, H.; Schaub, G.; Nam, S. S.; Jun, K. W.; Choi, M. J.; Kishan, G.; Lee, K. W.; Appl. Catal., A 1999, 186, 201.

36. Davis, B. H.; Fuel Process. Technol. 2001, 71, 157.

37. Dry. M. E.; Appl. Catal., A 1996, 138, 319.

38. van Steen, E.; Schulz, H.; Appl. Catal., A 1999, 186, 309.

39. Davis, B. H.; Catal. Today 2003, 84, 83. 
40. Tavasoli, A.; Nakhaeipour, A.; Sadaghiami, K.; Fuel Process. Technol. 2007, 88, 461

41. Luo, M.; Davis, B. H.; Appl. Catal., A 2003, 246, 171.

42. Pour, A. N.; Shahri, S. M. K.; Zamani, Y.; Zamanian, A.; J. Nat. Gas Chem. 2010, 19,193.

43. Gallegos, N. G.; Alvarez, A. M.; Cagnoli, M. V.; Bengoa, J. F.; Marchetti, S. G.; Mercader, R. C.; Yeramian, A. A.; J. Catal. 1996, 161, 132.

44. Wan, H.; Wu, B.; Zhang, C.; Xiang, H.; Li, Y.; J. Mol. Catal. A: Chem. 2008, 283, 33 .

45. Neathery, J. K.; Jacobs, G.; Sarkar, A.; Davis, B. H.; Separation of Fischer-Tropsch Wax from Ultrafine Iron Catalyst Particles, Center for Applied Energy Research/University of Kentucky: Lexington, 2005.

46. Sie, S. T.; Krishna. R.; Appl. Catal., A 1999, 186, 55.

47. Forghani, A. A.; Elekaei, H.; Rahimpour, M. R.; Int. J. Hydrogen Energy 2009, 34, 3965.

48. Arzamendi, G.; Diéguez, P. M.; Montes, M.; Odriozola, J. A.; SousaAguiar, E. F.; Gandía, L. M.; Chem. Eng. J. 2010, 160, 915.

49. Spath, P. L.; Dayton, D. C.; Technical and Economic Assessment of Synthesis Gas to Fuels and Chemicals with Emphasis on the Potential for Biomass-Derived Syngas, National Renewable Energy Laboratory: Colorado, 2003.

50. Aasberg-Petersen, K.; Hansen, J. H. B.; Christensen, T. S.; Dybkjaer, I. P.; Christensen, S.; Nielsen, C. S.; Madsen, S. E. L. W.; Rostrup-Nielsen, J. R.; Appl. Catal., A 2001, 221, 379.

51. Shah, L. S.; Thacker, P. S.; Quintana, M. E.; Song, R.; US pat. WO/2003/035590 2003.

52. Weick, L.; Nimmo, M.; Handbook of Petroleum Refining Processes, McGraw-Hill: Tulsa, 2004, chap. 15.2.

53. Furimsky, E.; Oil Gas Sci. Technol. 1999, 54, 597.

54. Boerrigter, H.; Calis, H. P.; Slort, D. J.; Bodenstaff, H.; Kaandorp, A. J.; den Uil, Rabou, H. L. P. L. M.; Gas Cleaning for Integrated Biomass Gasification (BG) and Fischer-Tropsch (FT) Systems: Experimental demonstration of two BG-FT systems ("Proof-of-Principle"), Energy Research Centre of the Netherlands: Petten, 2004.

55. Li, X.; Hagaman, E.; Tsouris, C.; Lee, J. W.; Energy Fuels 2003, 17, 69.

56. Pruet, R. B.; US pat. 7,276,105 B2 2007.

57. Klerk, A.; Tese de Doutorado, University of Pretoria, África do Sul, 2008 .

58. van Dijk, H. A. J.; Tese de Doutorado, Technische Universiteit Eindhoven, Holanda, 2001.

59. Wang, T.; Wang, J.; Jin, Y.; Ind. Eng. Chem. Res. 2007, 46, 5824.

60. White. C. M.; Jensen, K. L.; Rohar, P. C.; Tamilia, J. P.; Shaw, L. J.; Kickley, R. F.; Energy Fuels 1996, 10, 1067.

61. Kamata, H.; Nariai, K.; Ohara, H.; Japanese pat. JP2009214013-A 2009.

62. Kavalov, B.; Peteves, S. D.; Status and Perspectives of Biomassto-Liquid Fuels in the European Union, European Comission: Luxembourg, 2005
63. Almeida, E. L. F.; Bontempo, J. V.; Bicalho, R. G.; Comision de Integración Energetica Regional 2006, 15, 53.

64. Shen, J.; Schmetz, E.; Kawalkin, G. J.; Stiegel, G. J.; Winslow, J. C.; Kornosky, R. M.; Venkataraman, V. K.; Chaddock, J. S.; Cicero, D. C.; Jain, S. C.; Tennant, J. B.; Resumos do DEER Workshop, San Diego, USA, 2002

65. van Vliet, O. P. R.; Faaij, A. P.C.; Turkenburg, W. C.; Energy Convers. Manage. 2009, 50, 855.

66. http://web.mit.edu/aeroastro/partner/reports/proj17/altfuelfeasrpt.pdf, acessada em Outubro 2010.

67. Arzamendi, G.; Diéguez, P. M.; Montes, M.; Odriozola, J. A.; SousaAguiar, E. F.; Gandía, L. M.; Chem. Eng. J. 2009, 154, 168.

68. Chedid, R.; Kobrosly, M.; Ghajar, R.; Energy Policy 2007, 35, 4799.

69. Branco, D. A. C.; Szklo, A. S.; Schaeffer, R.; Energy 2010, 35, 118.

70. Wu, T.; Huang, Z.; Zhang, W.; Fang, J.; Yin, Q.; Energy Fuels 2007, 21, 1908.

71. Holmgren, K.; Hagberg. L.; Life Cycle Assessment of Climate Impact of Fischer-Tropsch Diesel Based on Peat and Biomass, Swedish Environmental Research Institute: Stockholm, 2009.

72. Universal Technology Corporation; Industrial Base Assessment of Alternative Fuels for Military Use. North American Technology and Industrial Base Organization, Ohio, 2010.

73. van Bibber, L.; Thomas, C.; Chaney, R.; Alaskan Coal Gasification Feasibility Studies-Healy Coal-to-Liquids Plant, National Energy Technology Laboratory/Department of Energy: Washington, 2007.

74. Chaney, R. E.; van Bibber, L. E.; Beluga Coal Gasification Feasibility Study, National Energy Technology Laboratory/Department of Energy: Washington, 2006.

75. BP; BP Statistical Review of World Energy June 2010, London, 2010.

76. Kiwi-Minsker, L.; Renken, A.; Catal. Today 2005, 110, 2.

77. Brophy, J.; $10^{\text {th }}$ PIN Meeting, Heriot-Watt University, Edinburgh, UK, 2004.

78. http://velocys-files.gripmanager.com/news_item/pdf/66/Velocys_ Update27.pdf, acessada em Outubro 2010.

79. http://www.netl.doe.gov/technologies/coalpower/gasification/database/ database.html, acessada em Fevereiro 2011.

80. Keshav, T. R.; Basu, S.; Fuel Process. Technol. 2007, 88, 493.

81. Khodakov, A. Y.; Braz. J. Phys. 2009, 139, 171.

82. http://www.compactgtl.com/petrobras.php, acessada em Outubro 2010.

83. Pua, L. M.; Rumbold, S. O.; First International Conference on microchannels and minichannels, Rochester, USA, 2003.

84. Rentech; Topics Catal. 2003, 4, 5.

85. http://www.davyprotech.com/pdfs/Modular Technology for GTL.pdf, acessada em Outubro 2010.

86. Agência Nacional do Petróleo (ANP); Anuário Estatístico Brasileiro de Petróleo, Gás Natural e Biocombustíveis 2010, ANP: Rio de Janeiro, 2010.

87. http://www.dicyt.com/noticia/tecnologia-nacional-para-extrair-petroleoe-gas-do-pre-sal, acessada em Julho 2010. 